\title{
Investigating the risk-benefit balance of substituting red and processed meat with fish
} in a Danish diet

Thomsen, Sofie Theresa; Pires, Sara Monteiro; Devleesschauwer, Brecht; Poulsen, Morten; Fagt, Sisse; Ygil, Karin Hess; Andersen, Rikke

\author{
Published in: \\ Food and Chemical Toxicology
}

Link to article, DOI:

10.1016/j.fct.2018.06.063

Publication date:

2018

Document Version

Peer reviewed version

Link back to DTU Orbit

Citation (APA):

Thomsen, S. T., Pires, S. M., Devleesschauwer, B., Poulsen, M., Fagt, S., Ygil, K. H., \& Andersen, R. (2018). Investigating the risk-benefit balance of substituting red and processed meat with fish in a Danish diet. Food and Chemical Toxicology, 120, 50-63. https://doi.org/10.1016/j.fct.2018.06.063

\section{General rights}

Copyright and moral rights for the publications made accessible in the public portal are retained by the authors and/or other copyright owners and it is a condition of accessing publications that users recognise and abide by the legal requirements associated with these rights.

- Users may download and print one copy of any publication from the public portal for the purpose of private study or research.

- You may not further distribute the material or use it for any profit-making activity or commercial gain

- You may freely distribute the URL identifying the publication in the public portal 


\section{Accepted Manuscript}

Investigating the risk-benefit balance of substituting red and processed meat with fish in a Danish diet

Sofie Theresa Thomsen, Sara Monteiro Pires, Brecht Devleesschauwer, Morten Poulsen, Sisse Fagt, Karin Hess Ygil, Rikke Andersen

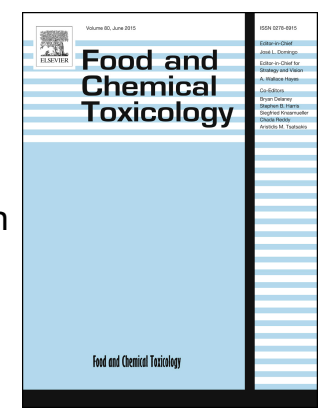

PII:

S0278-6915(18)30437-X

DOI:

10.1016/j.fct.2018.06.063

Reference: $\quad$ FCT 9884

To appear in: Food and Chemical Toxicology

Received Date: 20 April 2018

Revised Date: 28 June 2018

Accepted Date: 29 June 2018

Please cite this article as: Thomsen, S.T., Pires, S.M., Devleesschauwer, B., Poulsen, M., Fagt, S., Ygil, K.H., Andersen, R., Investigating the risk-benefit balance of substituting red and processed meat with fish in a Danish diet, Food and Chemical Toxicology (2018), doi: 10.1016/j.fct.2018.06.063.

This is a PDF file of an unedited manuscript that has been accepted for publication. As a service to our customers we are providing this early version of the manuscript. The manuscript will undergo copyediting, typesetting, and review of the resulting proof before it is published in its final form. Please note that during the production process errors may be discovered which could affect the content, and all legal disclaimers that apply to the journal pertain. 


\section{Investigating the Risk-Benefit Balance of Substituting Red and Processed Meat with Fish in a Danish Diet ${ }^{1}$}

Authors: Sofie Theresa Thomsen ${ }^{1 *}$, Sara Monteiro Pires ${ }^{1}$, Brecht Devleesschauwer ${ }^{2,3}$, Morten Poulsen $^{1}$, Sisse Fagt ${ }^{4}$, Karin Hess Ygil ${ }^{4}$, Rikke Andersen ${ }^{1}$

${ }^{1}$ Division of Diet, Disease Prevention and Toxicology, National Food Institute, Technical University of Denmark, Kemitorvet, Building 202, 2800 Kgs. Lyngby, Denmark

${ }^{2}$ Department of Epidemiology and Public Health, Sciensano, Juliette Wytsmanstreet 14, 1050 Brussels, Belgium

${ }^{3}$ Department of Veterinary Public Health and Food Safety, Faculty of Veterinary Medicine, Ghent University, Salisburylaan 133, 9820 Merelbeke, Belgium

${ }^{4}$ Division of Risk Assessment and Nutrition, National Food Institute, Technical University of Denmark, Kemitorvet, Building 202, 2800 Kgs. Lyngby, Denmark

* Corresponding author: Sofie Theresa Thomsen, Technical University of Denmark, National Food Institute, Kemitorvet, building 201, room 115, 2800 Kgs. Lyngby, Denmark.

Phone: +45 35887562; e-mail: sthth@food.dtu.dk

\footnotetext{
${ }^{1}$ Abbreviations: AI: Adequate Intake; Bw: Body weight; CHD: Coronary Heart Disease; CONTAM: Contaminants in the Food Chain; CRC: Colorectal Cancer; DALY: Disability-Adjusted Life Year; DANSDA: Danish National Survey of Diet and Physical Activity; DHA: Docosahexaenoic Acid; dl-PCB: Dioxin-Like Polychlorinated Biphenyls; DW: disability weight; EFSA: European Food Safety Authority; EPA: Eicosapentaenoic Acid; FAO: Food and Agriculture Organization of the United Nations; FBDG: Food-Based Dietary Guidelines; IQ: Intelligence Quotient; LE: Life Expectancy; MeHg: Methyl Mercury; NDA: Dietetic Products, Nutrition, and Allergies; P10: $10^{\text {th }}$ Percentile; P50: $50^{\text {th }}$ Percentile; P90: $90^{\text {th }}$ Percentile; RBA: Risk-Benefit Assessment; RR: Relative Risk; SC: Stomach Cancer; SD: Standard Deviation; TCDD: 2,3,7,8-Tetrachlorodibenzo-p-dioxin; TEF: Toxic Equivalency Factor; TEQ: Toxic Equivalents; TWI: Tolerable Weekly Intake; WHO: World Health Organization; YLD: Years Lived with Disability; YLL: Years of Life Lost.
} 


\section{Introduction}

Fish consumption and its associated health effects have been extensively studied during the last decades (EFSA Scientific Committee 2015). The beneficial effects of fish consumption are well established; however, so is the presence of various contaminants in fish such as methyl mercury (MeHg) and dioxins, potentially causing adverse effects on human health (FAO/WHO 2011). Riskbenefit assessment (RBA) is a tool used for weighting the risks and benefits of food consumption, and several RBAs have addressed the dual role of fish consumption on human health (Becker et al. 2007; Berjia et al. 2012; Cohen et al. 2005; Domingo 2016; EFSA Scientific Committee 2015; FAO/WHO 2011; FDA 2014; Gao et al. 2015; Hellberg et al. 2012; Hoekstra et al. 2013; Hsi et al. 2016; Jacobs et al. 2017; Persson et al. 2018; Sirot et al. 2012; van der Voet et al. 2007; VKM 2014; Zeilmaker et al. 2013). By qualitatively or quantitatively weighting the adverse health effects associated with contaminants in fish against the beneficial health effects associated with fish consumption, these RBAs have investigated whether increased fish consumption has a net beneficial or adverse effect on human health. The vast majority only dealt with fish alone and did not take substitution of other foods into consideration. However, increased consumption of fish is expected to lead to a decrease in the consumption of other foods, which may also be associated with risks and benefits that need to be addressed. The Danish food-based dietary guidelines (FBDG) of 2013 recommend an intake of $350 \mathrm{~g}$ of fish/week of which $200 \mathrm{~g}$ should be fatty fish. At the same time, the intake of red and processed meat is recommended to not exceed $500 \mathrm{~g} / \mathrm{week}$, and the intake of processed meat should be limited (Tetens et al. 2013a). One way for individuals that do not reach the recommended fish intake and that surpass the one for meats to fulfill these guidelines would be by substituting red and processed meats with fish. 
Quantification of the risk-benefit balance of foods for defining and supporting dietary guidelines has previously been encouraged (Rideout and Kosatsky 2017). In addition, the need for national estimates of disease burden and risk-benefit balance of food for public health policy has been stressed (Devleesschauwer et al. 2014b; Jacobs et al. 2017). The Disability-Adjusted Life Year (DALY) is a composite health metric commonly used in RBA and is also the preferred metric used for the World Health Organization estimates of the global burden of foodborne diseases (Devleesschauwer et al. 2015) and the Global Burden of Disease Study (Hay et al. 2017). It combines information on incidence, severity and duration of a disease or disability (Years Lived with Disability, YLD) with the standard expected Years of Life Lost (YLL) due to premature death and allows for a comparison across diseases (Devleesschauwer et al. 2014a). The difference in the sum of DALYs between a given reference scenario and one or more alternative scenarios gives information on an overall health gain or loss by a theoretical intervention in a population, expressed in loss of healthy life years.

In this study, we quantified the health impact of substituting red and processed meat with fish in the diet of the adult Danish population using DALYs as a common health metric. We compared the current consumption of fish and red and processed meat with four alternative scenarios in which red and processed meat were substituted with fish and the consumption of different fish species was considered.

\section{Methods}

\subsection{Identification of relevant health effects}

The relevant health effects associated with consumption of fish and red and processed meat were identified on the basis of official assessments by national and international authorities, regulatory 
agencies and expert groups within nutrition, toxicology, and medicine (EFSA CONTAM Panel 2012; EFSA NDA Panel 2014; EFSA Scientific Committee 2015; FAO/WHO 2011; FAO 2010; JECFA 2002; Larsen and Nørhede 2013; Norat et al. 2015, 2010; Nordic Council of Ministers 2014; Scientific Committee on Food 2000, 2001; US EPA 2012; Van Horn et al. 2008; VKM 2014; WCRF/AICR 2007). In addition, we performed a literature search for more recent systematic reviews and meta-analyses published after the literature search of the Norwegian Scientific Committee for Food Safety on April $1^{\text {st }} 2014$ (VKM 2014) for fish, and after the search of the Evidence Report behind the Danish FBDG on October $15^{\text {th }} 2012$ (Tetens et al. 2013) for red and processed meat. The search was conducted on June $18^{\text {th }} 2016$ and covered articles published up to that date. Health effects were included in the assessment if the epidemiological evidence was graded as "convincing" or "probable" according to the criteria set by the World Health Organization (WHO)/Food and Agriculture Organization of the United Nations (FAO) (WHO 2003). The evidence for toxicological health effects, however, in many cases cannot be graded higher than "possible" due to the constraints of studies investigating such effects (experimental animal studies, human case-control or cross-sectional studies). We chose to include health effects associated with toxicological hazards that were considered the most sensitive in animals and/or humans as defined for the establishment of health-based guidance values based on No/Lowest Observed Adverse Effect Levels. The health effects included in the RBA are listed in Table 1.

The health effects associated with fish consumption are mainly linked to the presence of nutrients and chemical contaminants in fish. Based on available evidence, we evaluated health effects associated with the chemical contaminants dioxin and dioxin-like (dl-) polychlorinated biphenyls (PCBs) and $\mathrm{MeHg}$, and two n-3 long-chain polyunsaturated fatty acids, docosahexaenoic acid (DHA) and eicosapentaenoic acid (EPA) (Table 1). The concentration of these compounds varies among fish species, and is dependent on the content of fat and muscle tissue. Specifically, the 
concentrations of dioxins, EPA and DHA are higher in fatty fish species, whereas $\mathrm{MeHg}$ accumulates in muscle tissue and is therefore found at higher concentrations in larger predatory fish species (EFSA CONTAM Panel 2012; EFSA Scientific Committee 2015). As identified by the Norwegian Scientific Committee for Food Safety, other contaminants than MeHg, dioxin and dlPCBs are present in fish, such as polybrominated flame retardants and fluorinated substances. However, exposure to these contaminants from fish was considered very low compared to the toxicity levels of these contaminants, and thus they were not considered as of concern (VKM 2014).

Various components have been suggested to associate consumption of red and processed meat with cancer, e.g. fat, protein, heme iron, and various contaminants such as N-nitroso compounds, heterocyclic amines, and polycyclic aromatic hydrocarbons (Bouvard et al. 2015; Domingo and Nadal 2017; Norat et al. 2010; WCRF/AICR 2007). However, although mechanistic evidence for the association between these individual components and cancer exists, their contribution to and the mechanism behind the observed association between consumption of red and processed meat and cancer is not known (Bouvard et al. 2015; Norat et al. 2010; WCRF/AICR 2007). Thus, we chose to base our modeling of the meat-associated health impact on red and processed meat as whole foods in this study (Table 1).

Both fish and red meat are also important sources of various minerals and vitamins. Red meat is an important contributor to the intake of especially B vitamins, iron, zinc, and selenium, and fish is an important source of vitamin D and selenium in the Danish diet (Pedersen et al. 2015). Due to methodological difficulties in assessing deficiency of iron, a particularly central micronutrient present in red meat, from dietary sources, and due to lack of good dose-response relationships to characterize the risks associated with iron deficiency (The Scientific Advisory Committee on Nutrition 2010) it was not possible to quantify the health impact of potential changes in iron intake due to the substitution. In order to not introduce bias due to inconsistency in included and excluded 
micronutrients, we chose not to consider the beneficial health effects associated with any micronutrients in this study. Furthermore, it was beyond the scope of the present study to assess acute adverse effects associated with microbiological contaminations potentially present in fish and meat. 


\begin{tabular}{|c|c|c|c|c|c|c|}
\hline Food & Compound & Health effect & $\begin{array}{l}\text { Subgroup } \\
\text { by } \\
\text { exposure }\end{array}$ & $\begin{array}{l}\text { DALY } \\
\text { contributions }\end{array}$ & Note & $\begin{array}{l}\text { Reference of } \\
\text { systematic reviews }\end{array}$ \\
\hline Fish & Whole fish & $\begin{array}{l}\text { Enhanced fetal } \\
\text { neurodevelopment } \\
\text { upon maternal } \\
\text { consumption }\end{array}$ & $\begin{array}{l}\text { Women, } \\
\text { age 15-49 } \\
\text { years }\end{array}$ & YLD & $\begin{array}{l}\text { The beneficial effects on fetal } \\
\text { neurodevelopment appear to be associated } \\
\text { with whole fish consumption and cannot } \\
\text { be explained only by the n-3 long-chain } \\
\text { polyunsaturated fatty acids in fish. No } \\
\text { recovery of intellectual disability is } \\
\text { assumed, thus duration was set to life } \\
\text { expectancy at birth, weighted by the } \\
\text { number of males and females born in } \\
\text { Denmark in } 2015 \text { (LE } \mathrm{L}_{0}=80.6 \text { years). }\end{array}$ & $\begin{array}{l}\text { (EFSA NDA Panel } \\
\text { 2014; FAO/WHO } \\
\text { 2011; FDA 2014) }\end{array}$ \\
\hline
\end{tabular}




\begin{tabular}{|c|c|c|c|c|c|c|}
\hline Fish & $\mathrm{MeHg}$ & $\begin{array}{l}\text { Compromised fetal } \\
\text { neurodevelopment } \\
\text { upon maternal } \\
\text { exposure }\end{array}$ & $\begin{array}{l}\text { Women, } \\
\text { age } 15-49 \\
\text { years }\end{array}$ & YLD & $\begin{array}{l}\text { Maternal MeHg exposure during } \\
\text { pregnancy is associated with adverse } \\
\text { effects on fetal neurodevelopment and has } \\
\text { been found to decrease the above stated } \\
\text { beneficial effects of whole fish } \\
\text { consumption on fetal neurodevelopment. } \\
\text { The same assumptions for the DALY } \\
\text { calculations as for enhanced fetal } \\
\text { neurodevelopment were used. }\end{array}$ & $\begin{array}{l}\text { (EFSA CONTAM } \\
\text { Panel 2012; } \\
\text { FAO/WHO 2011; } \\
\text { FDA 2014) }\end{array}$ \\
\hline Fish & $\begin{array}{l}\text { DHA + } \\
\text { EPA }\end{array}$ & $\begin{array}{l}\text { Decreased risk of } \\
\text { fatal CHD }\end{array}$ & $\begin{array}{l}\text { Age } \geq 15 \\
\text { years }\end{array}$ & YLL & $\begin{array}{l}\text { The evidence on an inverse association } \\
\text { with fatal CHD appears to be stronger for } \\
\text { DHA and EPA than for whole fish } \\
\text { consumption. Fatal CHD was assumed to } \\
\text { cause immediate death, thus no recovery } \\
\text { was included in the model. }\end{array}$ & $\begin{array}{l}\text { (EFSA NDA Panel } \\
\text { 2014; FAO/WHO } \\
\text { 2011; FAO 2010; } \\
\text { Tetens et al. 2013a). }\end{array}$ \\
\hline $\begin{array}{l}\text { Fish and } \\
\text { red }+ \\
\text { processed }\end{array}$ & $\begin{array}{l}\text { Dioxin + dl- } \\
\text { PCBs }\end{array}$ & $\begin{array}{l}\text { Decreased fertility in } \\
\text { male offspring }\end{array}$ & $\begin{array}{l}\text { Women, } \\
\text { age } 15-49 \\
\text { years }\end{array}$ & YLD & $\begin{array}{l}\text { One of the most sensitive endpoint } \\
\text { observed in both experimental animals and } \\
\text { epidemiological studies. Duration of male }\end{array}$ & $\begin{array}{l}\text { (JECFA 2002; } \\
\text { Scientific Committee } \\
\text { on Food 2000, 2001; }\end{array}$ \\
\hline
\end{tabular}




\begin{tabular}{|c|c|c|c|c|c|c|}
\hline meat & & & & & $\begin{array}{l}\text { infertility was set to } 29 \text { years based on the } \\
\text { assumption that a person will not be aware } \\
\text { of the disability before planning to start a } \\
\text { family. We considered it unlikely for this } \\
\text { to occur before the age of } 20 \text {. In addition } \\
\text { we assumed the same upper fertility age as } \\
\text { for women, i.e. age } 49 \text {. }\end{array}$ & $\begin{array}{l}\text { US EPA 2012; Van } \\
\text { Leeuwen et al. 2000; } \\
\text { WHO 2000) }\end{array}$ \\
\hline $\begin{array}{l}\text { Fish and } \\
\text { red }+ \\
\text { processed } \\
\text { meat }\end{array}$ & $\begin{array}{l}\text { Dioxin and } \\
\text { dl- PCBs }\end{array}$ & Hypothyroidism & $\begin{array}{l}\text { Age } \geq 15 \\
\text { years }\end{array}$ & YLD & $\begin{array}{l}\text { One of the most sensitive endpoint } \\
\text { observed in both experimental animals and } \\
\text { epidemiological studies. Hypothyroidism } \\
\text { was assumed non-fatal. We assumed that }\end{array}$ & $\begin{array}{l}\text { (Larsen and Nørhede } \\
\text { 2013; US EPA 2012; } \\
\text { Van Leeuwen et al. } \\
\text { 2000) }\end{array}$ \\
\hline Red meat & $\begin{array}{l}\text { Whole red } \\
\text { meat }\end{array}$ & $\begin{array}{l}\text { Increased risk of } \\
\text { colorectal cancer }\end{array}$ & $\begin{array}{l}\text { Age } \geq 15 \\
\text { years }\end{array}$ & YLD + YLL & $\begin{array}{l}\text { Red meat consumption has been found to } \\
\text { be associated with an increased risk of } \\
\text { CRC. The duration of CRC varies } \\
\text { depending on the course of disease which } \\
\text { is given by the natural disease history }\end{array}$ & $\begin{array}{l}\text { (Bouvard et al. 2015; } \\
\text { IARC 2015; Tetens } \\
\text { et al. 2013a; } \\
\text { WCRF/AICR 2007, } \\
\text { 2011) }\end{array}$ \\
\hline
\end{tabular}




\begin{tabular}{|c|c|c|c|c|c|c|}
\hline & & & & & model for CRC (see Table S14). & \\
\hline $\begin{array}{l}\text { Processed } \\
\text { meat }\end{array}$ & $\begin{array}{l}\text { Whole } \\
\text { processed } \\
\text { meat }\end{array}$ & $\begin{array}{l}\text { Increased risk of } \\
\text { colorectal cancer }\end{array}$ & $\begin{array}{l}\text { Age } \geq 15 \\
\text { years }\end{array}$ & YLD + YLL & $\begin{array}{l}\text { Processed meat consumption has been } \\
\text { found to be associated with an increased } \\
\text { risk of CRC. The same natural disease } \\
\text { history model for CRC used for red meat } \\
\text { consumption was used (see Table S14). }\end{array}$ & $\begin{array}{l}\text { (Bouvard et al. 2015; } \\
\text { IARC 2015; Tetens } \\
\text { et al. 2013a; } \\
\text { WCRF/AICR 2007, } \\
\text { 2011) }\end{array}$ \\
\hline $\begin{array}{l}\text { Processed } \\
\text { meat }\end{array}$ & $\begin{array}{l}\text { Whole } \\
\text { processed } \\
\text { meat }\end{array}$ & $\begin{array}{l}\text { Increased risk of } \\
\text { stomach non-cardia } \\
\text { cancer }\end{array}$ & $\begin{array}{l}\text { Age } \geq 15 \\
\text { years }\end{array}$ & YLD + YLL & $\begin{array}{l}\text { Processed meat was recently upgraded by } \\
\text { World Cancer Research Fund's } \\
\text { Continuous Update Project to be probably } \\
\text { associated with stomach non-cardia cancer. } \\
\text { The duration of SC varies depending on } \\
\text { the course of disease which is given by the } \\
\text { natural disease history model for SC (see } \\
\text { Table S14). }\end{array}$ & (WCRF/AICR 2016) \\
\hline
\end{tabular}


Table 1. Health effects associated with consumption of fish and red and processed meat included in the risk-benefit assessment based on available evidence and expert opinions. Abbreviations: CHD: coronary heart disease; CRC: colorectal cancer; DALY: DisabilityAdjusted Life Year, DHA: docosahexaenoic acid; dl-PCB: dioxin-like polychlorinated biphenyl; EPA: eicopentaenoic acid; LE : $_{0}$ life expectancy at age 0; MeHg: methyl mercury; SC: stomach cancer; YLD: Years Lived with Disability; YLL: Years of Life Lost.

\subsection{Data used in the model}

Consumption data from the Danish National Survey of Diet and Physical Activity (DANSDA), 2011-2013, were used for estimating the individual mean daily consumption of fish and meat in the Danish population (Pedersen et al. 2015). DANSDA is a nation-wide, cross-sectional survey of diet and physical activity in a representative sample of individuals in the Danish population, drawn from random sampling from the civil population registration system. The participants answered a precoded semi-closed food diary consisting of categories with common foods and dishes in the Danish diet (Knudsen et al. 2011). In our study, data were restricted to individuals that 1) reported for all (consecutive) 7 days, 2) had information on body weight, and 3) were at or above 15 years of age, giving a total population sample of 2,811 individuals.

Concentration data for both nutrients and contaminants were obtained from Danish food monitoring (DTU 2017; Larsen et al. 2002; Petersen et al. 2015b, 2015a). These data represent samples taken from foods of both Danish and non-Danish origin on the Danish market (DTU 2017; Larsen et al. 2002; Petersen et al. 2015b, 2015a). When information on the number of samples from different sources of food sampling was available, a mean weighted by the number of samples across food sampling sources was applied. If the number of samples was not available, all data sources were given the same weight.

We assumed that fish is the only source of DHA and EPA (see Table S2), even though a limited amount of $\alpha$-linoleic acid, found in various plant oils, can be converted into DHA and EPA (FAO 
2010). Likewise we did not include DHA and EPA intake from supplements. A minimum daily intake of approximately $250 \mathrm{mg}$ DHA and EPA for adult men and non-pregnant/non-lactating women and $300 \mathrm{mg}$ DHA plus EPA for pregnant/lactating women was recommended by FAO in 2010 (FAO 2010). The European Food Safety Authority (EFSA) Panel on Dietetic Products, Nutrition, and Allergies (NDA) proposed the same year to set an adequate intake (AI) of $250 \mathrm{mg}$ DHA plus EPA/day for adults and an additional 100-200 mg preformed DHA/day for pregnant and lactating women (EFSA NDA Panel 2010).

As for DHA and EPA, fish and other seafood are the only significant source of human $\mathrm{MeHg}$ exposure (see Table S5). MeHg is the most common form of organic mercury in food and constitute $80-100 \%$ of total mercury in fish and $50-80 \%$ in other seafood according to the EFSA Panel on Contaminants in the Food Chain (CONTAM) (EFSA CONTAM Panel 2012). When concentration data were only available for total mercury, we applied a conservative approach, i.e. we assumed that $100 \%$ and $80 \%$ of total mercury in fish and shellfish, respectively, is $\mathrm{MeHg}$ to avoid underestimating the health impact associated with $\mathrm{MeHg}$ exposure through fish consumption. The tolerable weekly intake (TWI) for MeHg was set to $1.3 \mu \mathrm{g} / \mathrm{kg}$ bw by the EFSA CONTAM panel in 2012 (EFSA CONTAM Panel 2012). The TWI corresponds to a daily exposure of $0.19 \mu \mathrm{g} / \mathrm{kg} \mathrm{bw}$.

Polychlorinated dibenzo- $p$-dioxins and polychlorinated dibenzofurans - hereafter referred to as dioxins - and dl-PCBs are persistent organic pollutants that remain in the environment for long periods of time. Dl-PCBs are PCBs that elicit toxicological responses similar to those by the most toxic congener of dioxins, 2,3,7,8-tetrachlorodibenzo-p-dioxin (TCDD) (FAO/WHO 2011). Exposure to a mixture of dioxin and dl-PCBs is usually estimated in terms of Toxic Equivalents (TEQs). TEQs are defined as the product of the concentration of each congener by it specific Toxic Equivalency Factor (TEF) (WHO 2000). The TEF of a compound indicates the potency of the given compound relative to TCDD, which has a reference value of 1 (Ahlborg et al. 1992; IARC 1997). 
The exposure to dioxin and dl-PCBs is collectively assessed by using concentration data for total TEQ, based on TEFs set by WHO in 2005 (Van den Berg et al. 2006). Humans are primarily exposed to dioxin and dl-PCBs from animal sources, such as fish, meat, and dairy products but also from other foods and the environment (Larsen and Nørhede 2013). We only assessed the foodassociated exposure to dioxin and dl-PCBs in this study. Concentrations of dioxin and dl-PCBs were given per $\mathrm{g}$ of fresh weight for fish and seafood (see Table S5) and per $\mathrm{g}$ of fat for other foods (see Table S4). Thus, the absolute concentrations of dioxins and dl-PCBs in other foods than fish were calculated based on the fat contents of these foods. A TWI of $14 \mathrm{pg}$ TEQ/kg bw (corresponding to on average $2 \mathrm{pg}$ TEQ/kg bw/day) was established for dioxin and dl-PCBs by the Scientific Committee on Food, European Commission in 2001 (Scientific Committee on Food 2001).

Data on incidence and mortality of studied health outcomes/diseases for 2015 were obtained from Danish health registries via the Danish eHealth Authority (The Danish National eHealth Authority). Population statistics for 2015 were obtained from Statistics Denmark (Statistics Denmark) (see Table S6).

\subsection{Alternative scenarios}

We defined four alternative scenarios to be compared with the current consumption of fish and meat in the Danish population. The alternative scenarios were based on the recommended minimum weekly intake of $350 \mathrm{~g}$ of cooked/prepared fish and a maximum weekly intake of $500 \mathrm{~g}$ of cooked red meat and processed meat as advised in the Danish FBDG (Pedersen et al. 2015; Tetens et al. 2013a). Fish and meat intake amounts per individual were given in cooked/prepared weights in DANSDA 2011-2013. To determine food intakes in the alternative scenarios, we gave the dietary 
guideline on fish the highest priority. Consequently, individual consumptions below $350 \mathrm{~g} / \mathrm{week}$ were increased to this level whereas no changes were made for individuals already consuming 350 $\mathrm{g}$ of fish/week or more. Based on assumptions on portion sizes (see Table S7) we estimated that a fish intake of $350 \mathrm{~g} /$ week can be achieved by consuming fish in two hot meals (100 $\mathrm{g}$ each) and five cold meals (five half Danish open-faced sandwiches, $30 \mathrm{~g}$ each) per week.

The increase in individual fish consumption was compensated by decreasing the consumption of red and processed meat. However, if the decrease in red or processed meat consumption for an individual was larger than the current consumption, meat consumption was set to zero. The consumption of red and processed meat was decreased according to the increase in fish consumption at the individual level by applying substitution factors. The substitution factors relied on the assumption that non-processed red meat is only consumed in hot meals and will be substituted by fish mainly consumed in hot meals, while processed meat is mainly consumed in cold meals and will be substituted by fish normally only consumed in cold meals in a Danish diet. The substitution factors were derived based on differences in typical portion sizes of fish, red meat, and processed meat (see Table S7) (Ygil 2013). The substitution factor used for substituting red meat with fish consumed in hot meals was 1.07, and the substitution factor for substituting processed meats with fish consumed in cold meals was 3. In other words, e.g. $10 \mathrm{~g}$ of processed meat (such as a slice of ham on a Danish open-faced sandwich), would be substituted by $30 \mathrm{~g}$ of fish consumed for cold meals (such as pickled herring).

We differentiated between fatty and lean fish, and specifically addressed tuna, a large predatory fish, in the alternative scenarios. Fish species were categorized into lean fish ( $\leq 5 \%$ fat) and fatty fish (> 5\% fat) (VKM 2014). Red meat was defined as beef, pork, lamb, and goat, and processed meats included any meats preserved by smoking, curing, salting, or addition of chemical preservatives (both red meat and poultry) (WCRF/AICR 2007). Game meat was also considered red 
meat. The ratio between red and processed meat was kept constant for each individual in all four alternative scenarios and was determined by the amount of meat consumed before substitution and the type of fish (for cold or hot meals) increased in the alternative scenarios. Thus, the four alternative scenarios only differed from each other in terms of fish species consumed.

The following scenarios were compared to the current Danish consumption of fish (reference scenario):

- Alternative scenario 1: consumption of 350g of a mix of lean and fatty fish/week

- Alternative scenario 2: consumption of $350 \mathrm{~g}$ of fatty fish/week.

- Alternative scenario 3: consumption of 350g of lean fish/week.

- Alternative scenario 4: consumption of 350g of tuna/week.

Thus, the fish consumed before substitution was also changed according to these fish species in the alternative scenarios. All alternative scenarios considered the same individual decreases in consumption of red and processed meat as a result of the substitution with fish, which was compared to the current consumption of red and processed meat. The proportions of the individual fish species eaten within each of the four alternative scenarios were based on the current preferences for the major fish species consumed in the Danish population (see Table S8).

\subsection{Exposure to food, nutrients and contaminants}

Observed individual mean daily consumption over 7 days was calculated based on individual-level consumption data from DANSDA 2011-2013 and considered a representative estimate of habitual (long-term) daily consumption in the Danish adult population ( $\geq$ age 15 years) (Bingham et al. 1994). In order to keep information on the dish and meal in which the food was consumed, consumption of individual foods was estimated based on data on meals. In other words, we used 
consumption data at the level of foods as consumed (e.g. pizza), and the intake of individual ingredients was estimated based on recipes (see Table S9, Table S10, and Table S11).

Consumption data for foods other than fish and meat contributing to dioxin exposure were provided on an ingredient level (e.g. milk and dairy products) due to the dispersion of these foods throughout the diet. Ingredient level consumption data were given as (primarily) raw weights (see Table S3).

Before estimating the exposure to contaminants and nutrients, fish and red meat intakes were converted into raw weights, assuming a water loss of $20 \%$ for fish and $25 \%$ for red meat. We assumed that preparation or cooking of foods does not cause a loss of the contaminants and nutrients in the foods considered in this study (Pedersen et al. 2015). Concentration data for nutrients and contaminants were available for processed meat, thus this type of meat was not converted into raw weights.

Exposure to contaminants was expressed per kg body weight (bw). The individual mean daily exposures to chemicals were estimated by the following equation:

$\sum_{n} \frac{I_{n} \cdot C_{n}}{b w}$

where $I_{n}$ is the individual mean daily intake of food $n$ in $\mathrm{g} /$ day, $C_{n}$ is the mean concentration of the chemical in food $n$ (in $\mu \mathrm{g} / \mathrm{g}$ for $\mathrm{MeHg}$ and $\mathrm{pg} \mathrm{TEQ} / \mathrm{g}$ for dioxin and dl-PCBs) and bw is the body weight of the given individual in $\mathrm{kg}$.

Exposure to nutrients was not expressed per kg bw as for chemicals, but in absolute exposure. The individual mean daily exposure to nutrients was estimated as follows:

$\sum_{n} I_{n} \cdot C_{n}$ 
where $I_{n}$ is the individual mean daily intake of food $n$ in $\mathrm{g} /$ day, $\mathrm{C}_{n}$ is the mean nutrient concentration in food $n$ (in $\mathrm{mg} / \mathrm{g}$ for DHA and EPA).

Exposure modeling was done by sex and 13 age groups (see Table S1). In order to also include individuals above the age of 75 years, the consumption data for 75 year-old participants were additionally extrapolated to ages $>75$ years, assuming similar consumption patterns.

Exposure was modeled by combining probabilities of exposure with (positive) exposure amounts. Probability of exposure was described by a Bernoulli distribution and exposure amounts by either a lognormal or Gamma distribution depending on the best fit according to Cramér-von Mises and Anderson-Darling goodness of fit tests. In the alternative scenarios, the empirical distributions were used for describing fish consumption and exposure to DHA and EPA, and MeHg due to a poor fit by both the lognormal and Gamma distributions (see Table S12).

\subsection{Calculating Disability-Adjusted Life Years}

The distribution of observed individual mean daily consumption/exposure was combined with doseresponse models to estimate the size of a given health effect associated with fish, red meat and processed meat consumption in the various scenarios. We quantified the disease burden of each health effect in terms of DALYs (YLD + YLL). YLD for health outcome $d$, sex $s$, and age $a$ was defined as:

$Y L D_{a, s_{a} a}-A C_{a, s, a} \cdot D_{a} \cdot D W_{a}$

where $A C_{d, s, a}$ is the annual number of cases with health outcome $d$ for sex $s$ and age $a, D_{d}$ is the duration of health outcome $d$ until remission or death, and $D W_{d}$ is the disability weight for health outcome $d$. The disability weight is a measure of good health, ranging from zero (full health) to one 
(death) (see Table S13) (Devleesschauwer et al. 2014a). YLL for health outcome $d$, sex $s$, and age $a$ was defined as:

$$
Y L L_{d, s, a}=A D_{d, s, a} \cdot S E Y L L_{s, a}
$$

where $A D_{d, s, a}$ is the annual number of deaths due to health outcome $d$ for sex $s$ and age $a$ and $S E Y L L_{s, a}$ is the standard expected years of life lost for sex $s$ and age $a$ (WHO 2017). Finally the disease burden for health outcome $d$ was summed over sex and age:

$D A L Y_{d}=\sum_{s} \sum_{a}\left(Y L D_{d_{t}, a}+Y L L_{d_{i}, s, a}\right)$

The contributions to the DALY estimates for the various health effects considered in this RBA are listed in Table 1. We applied either a "top-down" or "bottom-up" approach to estimate incidence $\left(A C_{d, s, a}\right)$ and mortality $\left(A D_{d, s, a}\right)$ of a disease, depending on the data available to describe an association or causation between consumption of a food or exposure to a compound and the disease (Gibb et al. 2015). When risk estimates (e.g. relative risk [RR]) from epidemiological or human intervention studies were available, we applied a "top-down" approach, starting from the current incidence or mortality in the population, which was combined with RR dose-response functions and exposure distributions to estimate incidence or mortality due to fish or meat consumption (fatal CHD and DHA plus EPA exposure, $\mathrm{CRC}$ and red and processed meat consumption, and non-cardia stomach cancer and processed meat consumption). We applied a "bottom-up" approach, using dose-response functions combined with exposure distributions when risk estimates were not available from epidemiological studies (i.e., maternal fish consumption/MeHg exposure and fetal neurodevelopment) and when data from experimental animal studies were applied (i.e., exposure to dioxins and dl-PCBs and hypothyroidism and male infertility). A more detailed description of the 
methods to calculate DALYs is given in the Supplemental Material (see Supplemental Material A) along with model input parameters (see Table S12), and disability weights (see Table S13).

The health impact of the change in food consumption and compound exposure in each alternative scenario was expressed as the DALY difference for outcome $d\left(\triangle D A L Y_{d, \text { alt }}\right)$ between the alternative scenario and the reference scenario (current consumption):

$\triangle D A L Y_{d, a l t}=D A L Y_{d, a l t}-D A L Y_{d, r e f}$

A $\triangle \mathrm{DALY}>0$ implies a health loss of the intervention, whereas a $\triangle \mathrm{DALY}<0$ implies a health gain. Likewise, the overall health impact of the substitution was expressed as the difference between the sum of DALYs over the diseases associated with the food consumption in the alternative scenario and the sum of DALYs over the diseases associated with the food consumption in the reference scenario:

$\Delta D A L Y_{a l t}=\sum_{d}\left(D A L Y_{d, a l t}-D A L Y_{d_{a} r e f}\right)$

We applied two-dimensional Monte Carlo simulation using the $m c 2 d$ package (Pouillot and Delignette-Muller 2010) in R version 3.4.1 (R Core Team 2017) for the DALY calculations, with 100,000 iterations for simulating variability and 1,000 iterations for uncertainty. The results of the simulations were reported as the mean of the variability dimension and the median of the uncertainty dimension along with the $95 \%$ uncertainty interval around the mean.

\subsection{Statistical analysis}

Two-tailed pseudo p-values were calculated for the DALY differences between each alternative scenario and the reference scenario to test whether the change was significantly different from zero: 


$$
\text { P-value }=2 \cdot \min \left(\operatorname{Pr}\left(\triangle D A L Y_{\text {alt }}>0\right), \operatorname{Pr}\left(\Delta D A L Y_{\text {alt }}<0\right)\right)
$$

Where probabilities $(\mathrm{Pr})$ were estimated as the proportion of the DALY difference simulations above or below zero, respectively. We applied a 5\% significance level. The statistical analyses were performed using R version 3.4.1 (R Core Team 2017).

\section{Results}

\subsection{Substitution of meat with fish}

The current mean and median daily consumption of fish were $31.5 \mathrm{~g} / \mathrm{day}$ and $23.2 \mathrm{~g} / \mathrm{day}$, respectively, with more than $78 \%$ of the study population not reaching the recommended level of $350 \mathrm{~g}$ of fish/week (i.e. $50 \mathrm{~g} /$ day); $14 \%$ of the study population had no fish consumption (Table 2). In addition, the consumption of red and processed meat was on average above the recommended maximum intake of $500 \mathrm{~g} / \mathrm{week}$ (i.e. approximately $70 \mathrm{~g} /$ day), with a mean daily intake of 115.2 $\mathrm{g} /$ day; $73 \%$ of the study population was above the recommended maximum consumption. Because some individuals already consumed more than $50 \mathrm{~g}$ of fish/day before substitution (22\%), the population mean consumption was slightly higher than the recommended minimum (56.5 g/day) after substitution. After the substitution, the consumption of total red and processed meat was on average decreased by $17 \mathrm{~g} /$ day, with a larger decrease for red meat (14.1 $\mathrm{g}$ decrease/day) compared to processed meat ( $2.8 \mathrm{~g}$ decrease/day). In contrast to the FBDG for fish, on average the recommended maximum consumption of $500 \mathrm{~g}$ of total red and processed meat/week was not met after the substitution (mean weekly consumption: $\sim 690 \mathrm{~g} /$ week) with 59\% of the study population above the recommended maximum 500g of total red and processed meat/week. 


\begin{tabular}{|l|l|l|l|l|l|}
\hline Scenario and food & Mean & SD & P10 & P50 & P90 \\
\hline Reference scenario & & & & & \\
\hline Fish & 31.5 & 32.1 & 0.0 & 23.2 & 73.4 \\
\hline Total red and & 115.2 & 67.6 & 44.6 & 101.1 & \\
\hline processed meat & & & & & 134.5 \\
\hline Red meat & 76.1 & 46.2 & 26.7 & 68.1 & 86.4 \\
\hline Processed meat & 39.0 & 38.6 & 4.3 & 28.3 & \\
\hline Alternative scenario & & & & & 73.4 \\
\hline Fish & 56.5 & 18.9 & 50.0 & 50.0 & 185.6 \\
\hline Total red and & 98.2 & 67.4 & 26.5 & 85.0 & \\
\hline processed meat & & & & & \\
\hline Red meat & 62.0 & 46.3 & 9.5 & 53.7 & 24.9 \\
\hline Processed meat & 36.2 & 38.4 & 0.4 & & \\
\hline
\end{tabular}

Table 2. Consumption amounts of fish, total (red and processed) meat, red meat, and processed meat (g/day) in Danish adults before and after the substitution. Abbreviations: P10: $10^{\text {th }}$ percentile; P50: 50 ${ }^{\text {th }}$ percentile (median); P90: $90^{\text {th }}$ percentile; SD: standard deviation.

\subsection{Exposure assessment}

The four alternative substitution scenarios were compared to the current consumption in the Danish adult diet. The ratio of lean to fatty fish varied between scenarios. The fraction of fatty and lean fish consumed in the alternative scenario 1 was based on the current preferences. The resulting percentage of fatty fish in the alternative scenario 1 was $53 \%$ and $44 \%$ for fish consumed in cold meals and hot meals, respectively, based on the current preferences (see Table S8). This amounts to approximately $168 \mathrm{~g}$ of fatty fish per week, thus just below half of the total fish consumption. Fatty 
fish constituted $100 \%$ in the alternative scenario 2, and lean fish $100 \%$ in the alternative scenarios 3 and 4.

Table 3 shows the exposures to DHA and EPA, MeHg, and dioxin and dl-PCBs in the reference scenario and the four alternative scenarios. Table 3 shows that the study population was on average above the AI of $250 \mathrm{mg}$ DHA and EPA/day set by FAO and the EFSA NDA panel (EFSA NDA Panel 2010; FAO 2010) before the substitution although half of the population (52\%) did not meet the AI. In contrast, the recommendation was reached for the whole population in the alternative scenario 1 and 2, whereas the intake of DHA and EPA was decreased compared to the reference scenario in scenario 3 and 4 ( $84 \%$ and $95 \%$ below $250 \mathrm{mg}$ DHA and EPA/day, respectively). The reason for this decrease can be the fact that the individual consumption of fish species before substitution was also changed in the alternative scenarios, thus all fatty fish consumed in the reference scenario was replaced by lean fish in the alternative scenarios 3 and 4 . The TWI for $\mathrm{MeHg}(1.3 \mu \mathrm{g} / \mathrm{kg}$ bw/week) was not exceeded in $99 \%$ of the study population in the reference or alternative scenarios except for scenario 4 where $98 \%$ exceeded the TWI. For dioxin and dl-PCB exposure, we estimated an increase in the mean exposure in the alternative scenarios 1 and 2, whereas only the fraction of individuals exceeding the TWI for dioxin and dl-PCBs (14 pg TEQ/kg bw/week) was increased in the alternative scenario 2 (from $2 \%$ to $5 \%$ ). However, the TWI was not exceeded in $99 \%$ of the study population in the alternative scenarios 1,3 , and 4 (Table 3). 


\begin{tabular}{|c|c|c|c|c|c|}
\hline $\begin{array}{l}\text { Compound and } \\
\text { scenario }\end{array}$ & Mean & SD & P10 & P50 & P90 \\
\hline \multicolumn{6}{|l|}{$\begin{array}{l}\text { DHA and EPA } \\
(m g / \text { day })^{a}\end{array}$} \\
\hline Reference scenario & 408.99 & 508.40 & 0.00 & 226.43 & 1056.26 \\
\hline Scenario 1 & 722.57 & 248.44 & 632.80 & 632.80 & 947.93 \\
\hline Scenario 2 & 1228.79 & 415.22 & 1082.10 & 1082.10 & 1609.76 \\
\hline Scenario 3 & 244.24 & 81.17 & 215.81 & 216.72 & 315.56 \\
\hline Scenario 4 & 152.26 & 50.88 & 134.69 & 134.69 & 197.61 \\
\hline \multicolumn{6}{|l|}{$\begin{array}{l}\mathrm{MeHg} \\
(\mu \mathrm{g} / \mathrm{kg} \mathrm{bw} / \mathrm{day})^{b}\end{array}$} \\
\hline Reference scenario & 0.029 & 0.044 & 0.00 & 0.017 & 0.063 \\
\hline Scenario 1 & 0.050 & 0.017 & 0.035 & 0.048 & 0.063 \\
\hline Scenario 2 & 0.053 & 0.010 & 0.025 & 0.033 & 0.042 \\
\hline Scenario 3 & 0.068 & 0.025 & 0.047 & 0.064 & 0.086 \\
\hline Scenario 4 & 0.36 & 0.088 & 0.22 & 0.30 & 0.37 \\
\hline \multicolumn{6}{|l|}{$\begin{array}{l}\text { Dioxin and dl-PCBs } \\
(\text { pg TEQ/kg bw/day })^{c}\end{array}$} \\
\hline Reference scenario & 0.73 & 0.49 & 0.31 & 0.61 & 1.31 \\
\hline Scenario 1 & 0.94 & 0.29 & 0.66 & 0.89 & 1.28 \\
\hline Scenario 2 & 1.29 & 0.40 & 0.92 & 1.21 & 1.73 \\
\hline Scenario 3 & 0.61 & 0.20 & 0.39 & 0.58 & 0.85 \\
\hline Scenario 4 & 0.72 & 0.22 & 0.49 & 0.68 & 1.00 \\
\hline
\end{tabular}


Table 3. Daily exposures to DHA and EPA, MeHg, and dioxin and dl-PCBs in the Danish adult population in the reference scenario and the four alternative scenarios. Abbreviations: Bw: body weight; DHA: docosahexaenoic acid; dl-PCB: dioxin-like polychlorinated biphenyl; EPA: eicosapentaenoic acid; P10: $10^{\text {th }}$ percentile; P50: $50^{\text {th }}$ percentile (median); P90: $90^{\text {th }}$ percentile; SD: standard deviation; TEQ: toxic equivalents.

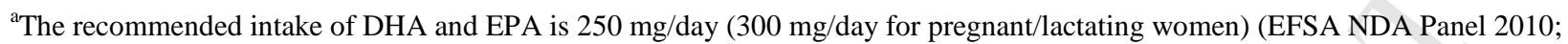
FAO 2010).

${ }^{\mathrm{b}}$ The tolerable daily intake for MeHg is $0.19 \mu \mathrm{g} / \mathrm{kg}$ bw/day (EFSA CONTAM Panel 2012).

${ }^{\mathrm{c}}$ The tolerable daily intake for dioxin and dl-PCBs is 2 pg TEQ/kg bw/day (Scientific Committee on Food 2001).

\subsection{Disability-Adjusted Life Years}

Figure 1 shows the health impact of the substitution in terms of the total DALY difference for each alternative scenario compared to the reference scenario. An overall health gain was observed in the alternative scenarios 1, 2, and 3, whereas a health loss was observed for the alternative scenario 4 (Figure 1). The overall DALY difference on the level of the whole population was -6986 DALYs ($8779,-5177)$ for the alternative scenario $1,-7203$ DALYs $(-9054,5422)$ for the alternative scenario 2, -3741 DALYs $(-4834,-2783)$ for the alternative scenario 3 , and 8608 DALYs $(3569,15336)$ for the alternative scenario 4 per year compared to the reference scenario. The DALY difference estimates were significantly different from zero in all alternative scenarios (pseudo P-values < 0.001). In other words, approximately 7,000 healthy life years could be gained each year in Denmark if the whole adult population substituted some of the red and processed meat in the diet with fish to reach the recommended intake of $350 \mathrm{~g}$ of fish/week (a mix of fatty and lean, or only fatty fish). In contrast, a smaller health gain was estimated when consuming only lean fish in the recommended amounts and an overall health loss was estimated when consuming only tuna. 


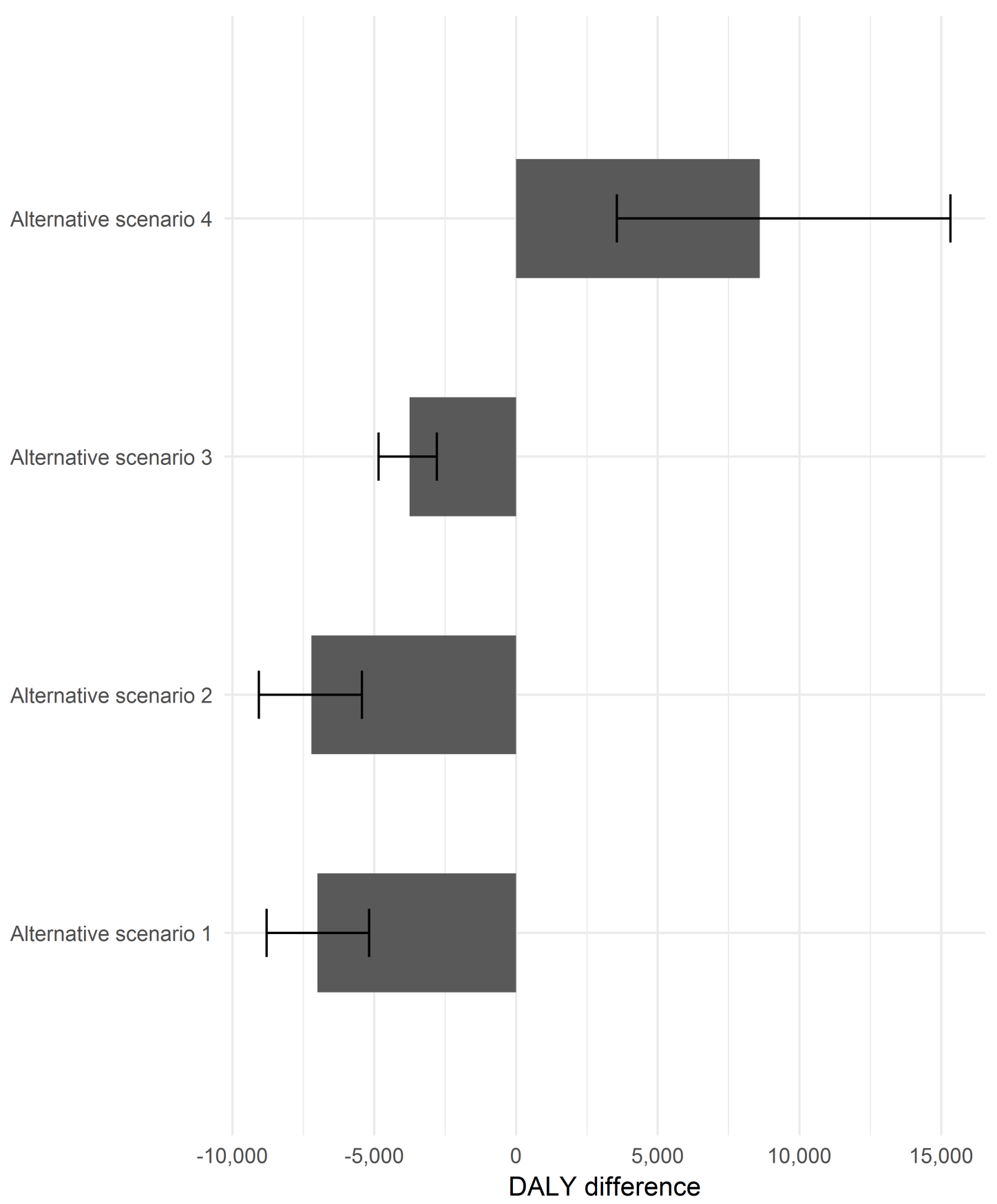

Figure 1 Difference in Disability-Adjusted Life Years (DALYs) by scenario. DALY difference between the current consumption and the four alternative scenarios for the total Danish adult population ( $\geq 15$ years; 4.7 million individuals). The bars represent the DALY differences between each of the four alternative scenarios and the current consumption as a measure of the health impact of the substitution. Error bars indicate $95 \%$ uncertainty intervals. 
The health impact of the substitution in terms of the DALY difference per 100,000 Danish adults ( $\geq$ 15 years) and number of cases of disease are shown for each of the health effects in each scenario in

Table 4 and Table 5, respectively. The largest beneficial health impact of the substitution was observed for enhanced neurodevelopment due to maternal fish consumption (alternative scenarios 1-4) and decreased risk of fatal coronary heart disease (CHD) due to an increased intake of DHA and EPA in the alternative scenarios 1-2. The largest adverse health impact of the substitution was observed for scenario 4 due to increased risk of compromised neurodevelopment associated with increased maternal $\mathrm{MeHg}$ exposure and increased risk of fatal CHD due to a decreased intake of DHA and EPA. 


\begin{tabular}{|c|c|c|c|c|c|c|c|c|c|}
\hline \multirow[t]{2}{*}{ Scenario } & \multicolumn{3}{|c|}{ Fish consumption } & \multicolumn{2}{|c|}{ Processed meat } & \multirow{2}{*}{$\begin{array}{l}\text { Red meat } \\
\text { CRC }\end{array}$} & \multicolumn{2}{|c|}{ Dioxin \& dl-PCBs } & \multirow{2}{*}{$\begin{array}{l}\text { Total } \triangle \text { DALY } \\
\text { per } 100,000\end{array}$} \\
\hline & $\begin{array}{l}\text { Increase in } \\
\text { IQ (whole } \\
\text { fish) }\end{array}$ & $\begin{array}{l}\text { Decrease in } \\
\text { IQ }(\mathrm{MeHg})\end{array}$ & $\begin{array}{l}\text { Fatal CHD } \\
\text { (DHA + EPA) }\end{array}$ & CRC & $\begin{array}{l}\text { Non-cardia } \\
\text { stomach } \\
\text { cancer }\end{array}$ & & $\begin{array}{l}\text { Male infertility } \\
\text { (dioxin and dl- } \\
\text { PCBs) }\end{array}$ & $\begin{array}{l}\text { Hypothyroidism } \\
\text { (dioxin and dl- } \\
\text { PCBs) }\end{array}$ & \\
\hline Scenario 1 & $\begin{array}{l}-49.83(- \\
69.41,- \\
33.82)\end{array}$ & $\begin{array}{l}5.92(1.92, \\
11.17)\end{array}$ & $\begin{array}{l}-86.81(- \\
117.80,-56.58)\end{array}$ & $\begin{array}{l}-4.81(-6.24, \\
-3.38)\end{array}$ & $\begin{array}{l}-0.33(-0.52,- \\
0.12)\end{array}$ & $\begin{array}{l}-12.83(- \\
18.79,-6.48)\end{array}$ & $0.00(0.00,0.00)$ & $0.00(-0.027,0.00)$ & $\begin{array}{l}-148.99(- \\
187.18,- \\
110.39)\end{array}$ \\
\hline Scenario 2 & $\begin{array}{l}-49.83(- \\
69.41,- \\
33.82)\end{array}$ & $\begin{array}{l}1.15(0.036, \\
2.39)\end{array}$ & $\begin{array}{l}-86.81(- \\
117.80,-56.58)\end{array}$ & $\begin{array}{l}-4.81(-6.24, \\
-3.38)\end{array}$ & $\begin{array}{l}-0.33(-0.52,- \\
0.12)\end{array}$ & $\begin{array}{l}-12.83(- \\
18.79,-6.48)\end{array}$ & $0.00(0.00,0.00)$ & $\begin{array}{l}0.00(-0.012, \\
0.00)\end{array}$ & $\begin{array}{l}-153.59(- \\
192.98,- \\
115.70)\end{array}$ \\
\hline Scenario 3 & $\begin{array}{l}-49.83(- \\
69.41,- \\
33.82)\end{array}$ & $\begin{array}{l}11.13(3.69, \\
21.11)\end{array}$ & $\begin{array}{l}-23.97(-24.63 \\
-19.82)\end{array}$ & $\begin{array}{l}-4.81(-6.24, \\
-3.38) \\
\end{array}$ & $\begin{array}{l}-0.33(-0.52,- \\
0.12)\end{array}$ & $\begin{array}{l}-12.83(- \\
18.79,-6.48)\end{array}$ & $0.00(0.00,0.00)$ & $\begin{array}{l}0.00(-0.028, \\
0.00)\end{array}$ & $\begin{array}{l}-79.85(-103.19 \\
-59.41)\end{array}$ \\
\hline Scenario 4 & $\begin{array}{l}-49.83(- \\
69.41,- \\
33.82)\end{array}$ & $\begin{array}{l}88.28 \\
(27.33, \\
184.03)\end{array}$ & $\begin{array}{l}161.51(89.22, \\
262.68)\end{array}$ & $\begin{array}{l}-4.81(-6.24, \\
-3.38)\end{array}$ & $\begin{array}{l}-0.33(-0.52,- \\
0.12)\end{array}$ & $\begin{array}{l}-12.83(- \\
18.79,-6.48)\end{array}$ & $0.00(0.00,0.00)$ & $\begin{array}{l}0.00(-0.028, \\
0.00)\end{array}$ & $\begin{array}{l}183.01(75.75 \\
326.31) \\
26\end{array}$ \\
\hline
\end{tabular}


Table 4. DALY difference per 100,000 Danish adult individuals per outcome in each alternative scenario compared to the reference scenario (95\% uncertainty intervals in parenthesis).

Abbreviations: CHD: coronary heart disease; CRC: colorectal cancer; DALY: disability-adjusted life years; DHA: docosahexaenoic acid; dl-PCB: dioxin-like polychlorinated biphenyl;

EPA: eicosapentaenoic acid; IQ: intelligence quotient; MeHg: methyl mercury. 


\begin{tabular}{|c|c|c|c|c|c|c|c|c|}
\hline & \multicolumn{3}{|c|}{ Fish consumption } & \multicolumn{2}{|c|}{ Processed meat } & \multirow{2}{*}{\begin{tabular}{|l} 
Red \\
meat \\
CRC
\end{tabular}} & \multicolumn{2}{|c|}{ Dioxin \& dl-PCBs } \\
\hline Scenario & $\begin{array}{l}\text { Intellectually } \\
\text { disabled (IQ } \\
<85 \text { ) due to } \\
\text { whole fish } \\
\text { consumption }\end{array}$ & $\begin{array}{l}\text { Intellectually } \\
\text { disabled (IQ } \\
<85 \text { ) due to } \\
\mathrm{MeHg} \\
\text { exposure }\end{array}$ & $\begin{array}{l}\text { Fatal } \\
\text { CHD }\end{array}$ & CRC & $\begin{array}{l}\text { Non- } \\
\text { cardia } \\
\text { stomach } \\
\text { cancer }\end{array}$ & & $\begin{array}{l}\text { Male } \\
\text { infertility }\end{array}$ & Hypothyroidism \\
\hline $\begin{array}{l}\text { Scenario } \\
1\end{array}$ & $\begin{array}{l}-1665(- \\
1967 ;-1357)\end{array}$ & $\begin{array}{l}177(67 ; \\
313)\end{array}$ & $\begin{array}{l}-174(- \\
564 ;- \\
10.91)\end{array}$ & $\begin{array}{l}-30.7 \\
(-182 ; \\
-5.16)\end{array}$ & $\begin{array}{l}-1.02(- \\
5.19 ;- \\
0.18)\end{array}$ & $\begin{array}{l}-88.0 \\
(- \\
1250,\end{array}$ & $\begin{array}{l}0.00 \\
(0.00 ; \\
0.00)\end{array}$ & $\begin{array}{l}0.00(-56.81 \\
0.00)\end{array}$ \\
\hline $\begin{array}{l}\text { Scenario } \\
2\end{array}$ & $\begin{array}{l}-1665(- \\
1967 ;-1357)\end{array}$ & $39(5.2 ; 73)$ & $\begin{array}{l}-174(- \\
564 ;- \\
10.91)\end{array}$ & $\begin{array}{l}-30.7 \\
(-182 ; \\
-5.16)\end{array}$ & $\begin{array}{l}-1.02(- \\
5.19 ;- \\
0.18)\end{array}$ & $\begin{array}{l}-88.0 \\
(- \\
1250, \\
-40.9)\end{array}$ & $\begin{array}{l}0.00 \\
(0.00 ; \\
0.00)\end{array}$ & $\begin{array}{l}0.00(-26.73 ; \\
0.00)\end{array}$ \\
\hline $\begin{array}{l}\text { Scenario } \\
3\end{array}$ & $\begin{array}{l}-1665(- \\
1967 ;-1357)\end{array}$ & $\begin{array}{l}322(127 ; \\
590)\end{array}$ & $\begin{array}{l}9.50(- \\
410 \\
226)\end{array}$ & $\begin{array}{l}-30.7 \\
(-182 ; \\
-5.16)\end{array}$ & $\begin{array}{l}-1.02(- \\
5.19 ;- \\
0.18)\end{array}$ & $\begin{array}{l}-88.0 \\
(- \\
1250, \\
-40.9)\end{array}$ & $\begin{array}{l}0.00 \\
(0.00 ; \\
0.00)\end{array}$ & $\begin{array}{l}0.00(-61.55 ; \\
0.00)\end{array}$ \\
\hline $\begin{array}{l}\text { Scenario } \\
4\end{array}$ & $\begin{array}{l}-1665(- \\
1967 ;-1357)\end{array}$ & $\begin{array}{l}2508(830 ; \\
4897)\end{array}$ & $\begin{array}{l}563 \\
(30.20 ; \\
854)\end{array}$ & $\begin{array}{l}-30.7 \\
(-182 ; \\
-5.16)\end{array}$ & $\begin{array}{l}-1.02(- \\
5.19 ;- \\
0.18)\end{array}$ & $\begin{array}{l}-88.0 \\
(- \\
1250, \\
-40.9)\end{array}$ & $\begin{array}{l}0.00 \\
(0.00 ; \\
0.00)\end{array}$ & $\begin{array}{l}0.00(-61.55 \\
0.00)\end{array}$ \\
\hline
\end{tabular}

Table 5. Extra number of cases by health outcome in each alternative scenario compared to the reference scenario (95\% uncertainty intervals in parenthesis).Abbreviations: CHD: coronary heart disease; CRC: colorectal cancer; DALY: disability-adjusted life years; 
DHA: docosahexaenoic acid; dl-PCB: dioxin-like polychlorinated biphenyl; EPA: eicosapentaenoic acid; IQ: intelligence quotient; MeHg: methyl mercury.

The relative contribution of the individual health effects to the overall DALY difference estimate is visually presented in Figure 2.

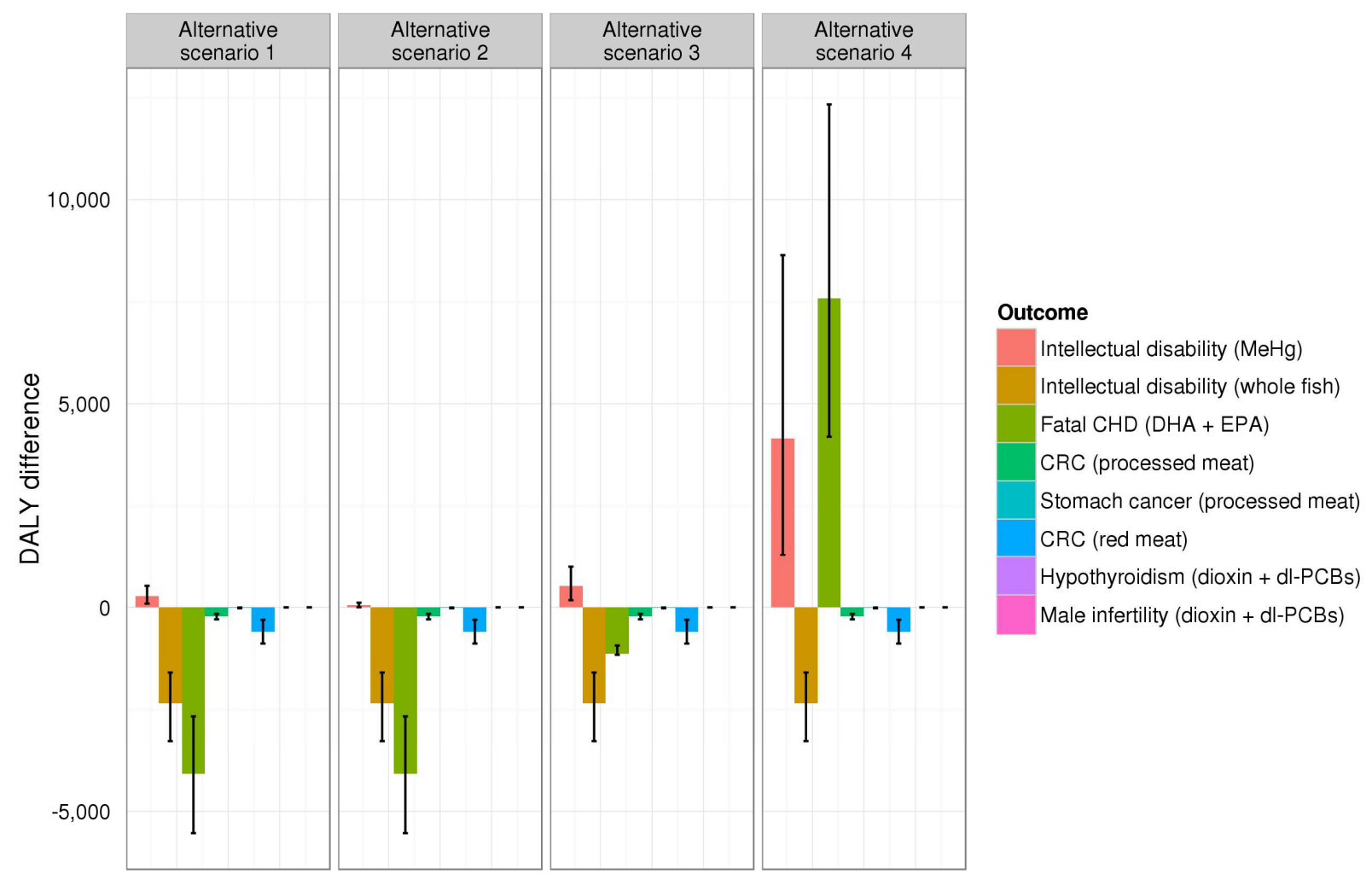

Figure 2 Difference in Disability-Adjusted Life Years (DALYs) by scenario and outcome. Contribution of each health outcome to the overall DALY difference estimates for each alternative scenario for the total Danish adult population ( $\geq 15$ years; 4.7 million individuals). Each bar represents the health impact of the substitutions on individual health effects. Error bars indicate $95 \%$ uncertainty intervals.

Abbreviations: CRC: colorectal cancer; DALY: disability-adjusted life years; DHA: docosahexaenoic acid; dl-PCB: dioxin-like polychlorinated biphenyl; DW: disability weight; EPA: eicosapentaenoic acid; MeHg: methyl mercury. 


\section{Discussion}

In this study we estimated the risk-benefit balance of substituting red and processed meat with fish in a Danish adult diet and investigated the health impact of consuming different types of fish (mix, lean, fatty and predatory) to fulfill the intake recommended by the Danish FBDG. To our knowledge, this is the first RBA that quantifies the health impact of substitution of foods in terms of DALYs. We found that on a population level up to 7,000 healthy years of life could be gained if all Danish adults increased their fish consumption to $350 \mathrm{~g} /$ week and correspondingly lowered the consumption of red and processed meat. Our results show that consumption of a mix of the average preferred fish species in Denmark or consumption of only fatty fish would be associated with the highest benefit in these amounts. In contrast, consuming only lean fish would be associated with a smaller health gain, and an overall health loss was estimated when consuming $350 \mathrm{~g}$ of tuna/week. By quantifying the health impact of adherence to dietary guidelines, our study provides evidence for national public health policy making.

Our results show that women in the fertile age are a particularly sensitive subgroup in the population when considering the health effects associated with fish consumption. Three out of eight health effects included in the RBA specifically concern this subgroup. Particularly the effects on fetal neurodevelopment (MeHg and whole fish consumption) contribute to the overall DALY difference in the various substitution scenarios compared to the reference scenario. The adverse effects on male fertility due to changes in prenatal dioxin and dl-PCB exposure resulting from the substitution appear to be insignificant and almost negligible. Maternal hypothyroidism has been associated with adverse effects on fetal neurodevelopment (Boas et al. 2006; Haddow et al. 1999; US EPA 2012), which we did not account for in our model due to the lack of a clear dose-response relationship. Despite an increase in the mean exposure to dioxin and dl-PCBs in the alternative 
scenarios 1-2, our model estimated no extra cases of hypothyroidism in these scenarios, thus no increased dioxin-induced negative impact on neurodevelopment after substitution was anticipated.

The overall health impact of the substitutions we investigated was mainly attributed to the increased fish consumption and the change in fish species consumed, whereas the decrease in consumption of red and processed meat appeared to only explain a minor part of the total DALY difference (Table 4 and Figure 2). As the guideline on limiting red and processed meat consumption to below 500 $\mathrm{g} /$ week was not met in more than half of the study population after substitution, this is not surprising. Likewise, a larger part of the health impact of the decrease in meat consumption was attributed to the decrease in red meat when compared to the decrease in processed meat consumption. Although processed meat is associated with increased risk of both non-cardia stomach cancer and CRC, and red meat is only associated with increased risk of CRC (and with a lower RR than processed meat (WCRF/AICR 2011)), the larger decrease in consumption of red meat (mean change: $14.1 \mathrm{~g} /$ day) when compared to the decrease in consumption of processed meat (mean change: $2.8 \mathrm{~g} /$ day) showed a larger effect on the overall health impact of the substitution.

Meanwhile, as mentioned in section 2.1., both fish and meat are important contributors to the intake of various micronutrients in the Danish diet. Thus, although only adverse health effects were included for consumption of red and processed meat in this study, we emphasize that this food group is also an important source of vitamins and minerals (Pedersen et al. 2015). However, another study investigated the impact on macro- and micronutrient intake when decreasing the consumption of red and processed meat and substituting with other foods, including fish, in the Nordic diet, and showed no marked changes in intake (Tetens et al. 2013b). It was noted that vitamin D and iron intakes were already below the recommendations in the Nordic countries, and did not change considerably due to the decrease in red and processed meat consumption. 
The differences in the health impact between the four alternative scenarios are explained mainly by the ratio of fatty to lean fish. Fatty fish constituted approximately $50 \%$ of all fish consumed in the alternative scenario $1,100 \%$ in the alternative scenario 2 , and $0 \%$ in the alternative scenarios 3 and 4. The scenarios that considered a higher consumption of fatty fish led to a higher intake of the fatty acids, DHA and EPA, which are associated with a decreased risk of fatal CHD (Mozaffarian and Rimm 2006). In addition, these scenarios also led to a lower exposure to $\mathrm{MeHg}$ (Table 3). This may be explained by the lower MeHg concentrations in the most frequently consumed fatty fish in Denmark compared to the most frequently consumed lean fish (see Table S5 and Table S8). Despite a higher consumption of fish in the alternative scenarios 3 and 4, the mean intake of DHA and EPA decreased compared to the current consumption due to the lower concentration of these fatty acids in lean fish. Thus, the overall health loss observed in the alternative scenario 4 cannot be attributed only to the higher exposure to $\mathrm{MeHg}$ (mean exposure: $0.36 \mu \mathrm{g} / \mathrm{kg}$ bw/day compared to $0.029 \mu \mathrm{g} / \mathrm{kg}$ bw/day in the reference scenario) and the associated adverse effects on fetal neurodevelopment but also particularly to a decreased intake of DHA and EPA in this scenario (mean intake: 152.26 $\mathrm{mg} /$ day compared to $408.99 \mathrm{mg} /$ day in the reference scenario), leading to a higher incidence of fatal CHD. We note that the concentration data for DHA and EPA in tuna that we applied for the exposure modeling were only based on canned tuna (Table S2).

The studies behind the dose-response relationships used for modeling the beneficial effects of fish consumption described upper limits of fish consumption above which no further benefit was observed (FAO/WHO 2011; Hibbeln et al. 2007; Mozaffarian and Rimm 2006). Both limits (30.5 g of fish/day for beneficial neurodevelopmental effects and $250 \mathrm{mg}$ DHA and EPA/day for fatal CHD prevention) correspond to approximately $200 \mathrm{~g}$ of fish/week, in the latter case exclusively fatty fish (Dietary Guidelines Advisory Committee 2010). According to the Danish FBDG, around $200 \mathrm{~g}$ of the recommended $350 \mathrm{~g}$ of fish/week should be fatty (Tetens et al. 2013a). Our study was 
inconclusive in determining the increased benefit of consuming $350 \mathrm{~g}$ of fish/week relative to only $200 \mathrm{~g}$ of fatty fish/week. Such increase in benefit was expected to be primarily related to the increase in micronutrient intake (e.g. vitamin D) and a decreased consumption of red and processed meat. We did not quantify the effects of changes in micronutrient intake due to the substitutions, which could however have helped clarifying the size of the increased benefit.

To our knowledge, no quantitative RBAs of red and processed meat consumption have been conducted. The burden of disease of high consumption of red and processed meat has been estimated by the Global Burden of Disease Study (GBD 2016 Risk Factor Collaborators 2017; Lim et al. 2012) and was also recently addressed in a national Norwegian burden of disease study (Sælensminde et al. 2016). Both studies quantified the health loss due to the current consumption of red and processed meat compared to a theoretical minimum risk exposure level (14.3 $\mathrm{g}$ of red meat/day and $7.2 \mathrm{~g}$ of processed meat/day). Norwegian high red meat consumption only constituted a small fraction of the total burden of dietary risk factors (approximately 84 DALYs/100,000 per year) however, processed meat was estimated to be the fourth leading cause of diet-associated disease in Norway, causing approximately 400 DALYs/100,000 per year (Sælensminde et al. 2016). Other health effects than CRC were included in the study (ischemic heart disease, diabetes mellitus, and CRC, and not non-cardia stomach cancer for processed meat) and the burden of CRC due to consumption of red and processed meat only constituted approximately 40 DALYs/100,000 per year and 46 DALYs/100,000 per year, respectively. Meanwhile, differences in e.g. definition of consumption scenarios, disease model, incidence, and mortality make it difficult to make a valid comparison between these results and ours. Had we included the same health effects as in the above mentioned studies, we may have had estimated a larger impact of the substitution of red and processed meat. However, we did not find the evidence strong enough for inclusion in our study. 
The risks and benefits associated with fish consumption have been extensively studied over the past decade (Becker et al. 2007; Berjia et al. 2012; Cohen et al. 2005; Domingo 2016; EFSA Scientific Committee 2015; FAO/WHO 2011; FDA 2014; Gao et al. 2015; Hellberg et al. 2012; Hoekstra et al. 2013; Hsi et al. 2016; Jacobs et al. 2017; Persson et al. 2018; Sirot et al. 2012; van der Voet et al. 2007; VKM 2014; Zeilmaker et al. 2013). All RBAs of fish have reached conclusions coherent with the outcome of our RBA, estimating that nutritional benefits generally outweighed the toxicological risks of fish consumption in the general population at moderate intakes and when exposures to contaminants were low. Hoekstra et al. reached similar overall results when investigating the impact of increasing the Dutch fish consumption to $200 \mathrm{~g}$ and $500 \mathrm{~g} /$ week (Hoekstra et al. 2013). Hoekstra and colleagues also accounted for variability in the final DALY difference and found that, on average, (young) Dutch women experience a smaller benefit of the increase in fish consumption compared to Dutch men, primarily due to health loss of unborn children. Van der Voet et al. also accounted for variability in an RBA of substituting a fraction of Dutch red meat consumption with fish by estimating individual probabilities of being below the Dutch AI of DHA and EPA (0.45 $\mathrm{g} /$ day) and above the tolerable daily intake for dioxin (2 pg/kg bw/day) (van der Voet et al. 2007). By simultaneously modeling the probabilities of transgressing these limits, they found a substitution of $25 \%$ of red meat with either salmon or a mix of fatty fish to be the most optimal scenario.

In an RBA of fish, Zeilmaker et al. found great variation in the risk-benefit balance among 33 fish species. This study focused on neurodevelopmental effects in unborn children attributed to maternal fish consumption and found an overall adverse effect of maternal fish consumption for the majority of the fish species considered (Zeilmaker et al. 2013). Zeilmaker and colleagues based their doseresponse model describing beneficial neurodevelopmental effects of fish consumption on the maternal intake of DHA. However, according to the EFSA NDA panel, the beneficial neurodevelopmental effects of fish consumption during pregnancy cannot be solely attributed to this 
fatty acid (EFSA NDA Panel 2014). By basing our model on maternal fish consumption, we also covered the beneficial neurodevelopmental effects of other nutrients in fish such as iodine (EFSA NDA Panel 2014). This may explain why the adverse effects of $\mathrm{MeHg}$ on neurodevelopment outweighed the beneficial effects of maternal fish consumption in the RBA by Zeilmaker et al., but not in our study, except when consuming large predatory fish species in high quantities.

Furthermore, the beneficial effect of fish consumption on neurodevelopment observed in our RBA is likely an underestimate of the true beneficial effect, as the dose-response relation we applied was not adjusted for maternal $\mathrm{MeHg}$ exposure (exposure assumed equal to the mean exposure in the British population of $0.05 \mu \mathrm{g} / \mathrm{kw} /$ day) (FDA 2014; Hibbeln et al. 2007). However, results from an American observational cohort showed that increased maternal fish intake was associated with a higher beneficial effect in the child when adjusting for maternal $\mathrm{MeHg}$ exposure (Oken et al. 2008b). The same study showed that the association between MeHg exposure and adverse neurodevelopmental effects were strengthened when adjusting for maternal fish intake. To be able to investigate potential limitations of increasing consumption of various types of fish with varying $\mathrm{MeHg}$ concentrations with a certain safety margin, we chose to apply a conservative approach and model both the non-MeHg adjusted beneficial effects of fish consumption and the adverse effects of $\mathrm{MeHg}$ exposure. Even though we may overestimate the adverse effects of $\mathrm{MeHg}$, our model supports the findings from other cohort studies, including a Danish birth cohort that found an overall beneficial effect of maternal fish consumption on fetal neurodevelopment when exposures to MeHg are low (Oken et al. 2005, 2008b, 2008a). However, our study adds insight in terms of the potential consequences of changing preferences towards large predatory fish species such as tuna. The monitoring data used in this study clearly showed that the concentration of MeHg in tuna was particularly higher than other (smaller) predatory fish species consumed in Denmark with around a 10-fold higher MeHg concentration (Table S5). While tuna showed a concentration of $0.31 \mu \mathrm{g}$ 
$\mathrm{MeHg} / \mathrm{g}$ fresh weight, fish such as cod, pollock, mackerel, Greenland halibut, flounder, and eel had concentrations in the range $0.052-0.072 \mu \mathrm{g} / \mathrm{g}$ fresh weight. WHO particularly highlighted shark, king mackerel, and swordfish, in addition to tuna as large predatory fish which may have high concentrations of MeHg (WHO 2008). Data on consumption of these fish species were not given in DANSDA, indicating a low intake in Denmark, and thus leaving tuna as the main concern for the Danish population.

In line with our findings, a recent risk assessment of $\mathrm{MeHg}$ exposure from fish consumption in five European countries found that frequent consumption of large predatory fish species, and in particular consumption of tuna, poses a potential risk of exceeding the TWI for MeHg (Jacobs et al. 2017). The authors recommended substituting large predatory and lean fish species with small fatty fish to increase benefits and decrease risks associated with fish consumption, coherent with the overall message of our RBA. Though others have stressed the risks of increasing the consumption of fatty fish species due to higher concentrations of dioxins and dl-PCBs (Sioen et al. 2008), we did not estimate an increased risk of dioxin-associated health effects when consuming $350 \mathrm{~g}$ of fatty fish/week compared to the current fish consumption.

Our substitution model was based on deterministic approaches, assuming that all individuals would substitute in the same manner. Thus, our model did not take variability in the substitution or in fish and meat preferences into account apart from individual baseline consumption. However, the Danish population may be very heterogeneous in the behavior concerning food substitution and in addition may also vary in what foods to substitute. The data, assumptions and models applied in this RBA all contribute to the uncertainty in the overall health impact of the substitutions we investigated. We were able to quantify some but not all of this uncertainty. Table 6 lists the sources of unquantified uncertainty in our study and explains the potential impact on the final results. We 
generally applied a conservative approach and overestimated especially toxicological risks. Still, the impact and direction of other sources of uncertainties are difficult to characterize.

\begin{tabular}{|c|c|c|}
\hline & Source of uncertainty & Impact \\
\hline \multirow[t]{3}{*}{ Health outcome } & $\begin{array}{l}\text { Identification of relevant } \\
\text { compounds }\end{array}$ & $\begin{array}{l}\text { There may be other compounds with } \\
\text { adverse/beneficial effects present in fish and red } \\
\text { and processed meat that have not been accounted } \\
\text { for in this RBA. }\end{array}$ \\
\hline & $\begin{array}{l}\text { Identification of relevant } \\
\text { health effects }\end{array}$ & $\begin{array}{l}\text { There may be other health effects associated with } \\
\text { consumption of fish and red and processed meat } \\
\text { which was not included in this RBA. }\end{array}$ \\
\hline & $\begin{array}{l}\text { Identification of relevant } \\
\text { subgroups }\end{array}$ & $\begin{array}{l}\text { There may be other relevant subgroups in relation } \\
\text { to the health effects considered in this RBA. }\end{array}$ \\
\hline \multirow[t]{2}{*}{$\begin{array}{l}\text { Exposure } \\
\text { assessment }\end{array}$} & $\begin{array}{l}\text { Uncertainty in } \\
\text { consumption data }\end{array}$ & $\begin{array}{l}\text { Over- or under-estimation of consumption. We } \\
\text { did not exclude under- and over-reporters in the } \\
\text { dietary survey. In addition, we did not adjust for } \\
\text { within-individual variability in consumption } \\
\text { which may cause overestimation of upper and } \\
\text { lower tails of distributions of consumption } \\
\text { amounts. }\end{array}$ \\
\hline & $\begin{array}{l}\text { Uncertainty in } \\
\text { concentration data }\end{array}$ & $\begin{array}{l}\text { There may be large uncertainty associated with } \\
\text { measuring nutrient and contaminant } \\
\text { concentrations in food. In addition, food }\end{array}$ \\
\hline
\end{tabular}




\begin{tabular}{|c|c|c|}
\hline & & $\begin{array}{l}\text { processing was not accounted for in our exposure } \\
\text { assessment. }\end{array}$ \\
\hline & $\begin{array}{l}\text { Uncertainty in } \\
\text { substitution model }\end{array}$ & $\begin{array}{l}\text { The established substitution factors are associated } \\
\text { with uncertainty which causes uncertainty in the } \\
\text { exposure assessment in the alternative scenarios } \\
\text { and around the final DALY difference estimate. }\end{array}$ \\
\hline & $\begin{array}{l}\text { Choice of model to } \\
\text { describe exposure } \\
\text { distributions }\end{array}$ & May over- or under-estimate exposures. \\
\hline & $\begin{array}{l}\text { Uncertainty in measured } \\
\text { bw }\end{array}$ & $\begin{array}{l}\text { We applied measured (non self-reported) bw data } \\
\text { and uncertainty would therefore primarily be } \\
\text { associated with the scale used in the dietary } \\
\text { survey. }\end{array}$ \\
\hline \multirow[t]{3}{*}{$\begin{array}{l}\text { Health impact } \\
\text { characterization }\end{array}$} & $\begin{array}{l}\text { Choice of dose-response } \\
\text { modeling of animal data }\end{array}$ & $\begin{array}{l}\text { Uncertainty is associated with the fitted dose- } \\
\text { response model to describe dioxin and dl-PCB } \\
\text { induced health effects which may lead to } \\
\text { uncertainty around the dose estimated to cause an } \\
\text { adverse effect in rats. }\end{array}$ \\
\hline & Interspecies extrapolation & $\begin{array}{l}\text { We did not quantify the uncertainty associated } \\
\text { with extrapolation factors applied to convert } \\
\text { dioxin and dl-PCB effect doses in animal to } \\
\text { humans; however, the uncertainty may be large. }\end{array}$ \\
\hline & Intraspecies extrapolation & $\begin{array}{l}\text { We did not quantify the uncertainty associated } \\
\text { with extrapolation factors applied to account for }\end{array}$ \\
\hline
\end{tabular}




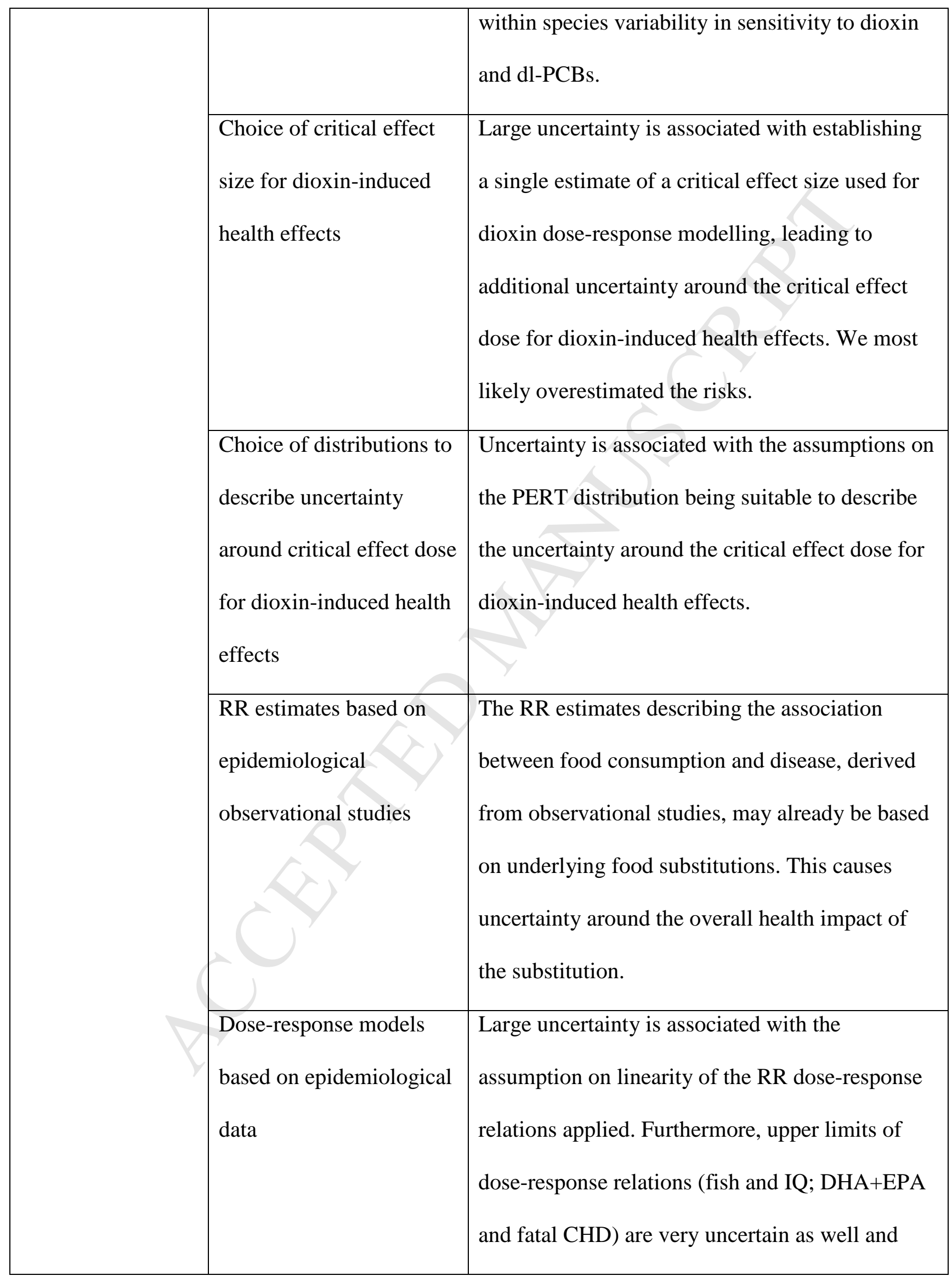




\begin{tabular}{|c|c|c|}
\hline & & $\begin{array}{l}\text { likewise it is uncertain if there may be } \\
\text { upper/lower limits for the other RR dose-response } \\
\text { models applied above/below which there is no } \\
\text { effect. We most likely underestimated the } \\
\text { benefits associated with the substitution. }\end{array}$ \\
\hline \multirow[t]{3}{*}{ DALY estimation } & $\begin{array}{l}\text { Choice of distributions to } \\
\text { describe uncertainty } \\
\text { around DWs }\end{array}$ & $\begin{array}{l}\text { Uncertainty is associated with the assumptions on } \\
\text { the PERT distribution being suitable to describe } \\
\text { the uncertainty around the DWs. }\end{array}$ \\
\hline & $\begin{array}{l}\text { Choice of onset and } \\
\text { duration of disease }\end{array}$ & $\begin{array}{l}\text { Large uncertainty associated with the } \\
\text { assumptions on onset and duration of disease } \\
\text { which may lead to either over- or under- } \\
\text { estimation of the final DALY estimates. } \\
\text { Likewise, we assumed no time-lag from exposure } \\
\text { to disease which is also associated with great } \\
\text { uncertainty. In contrast to all other health effects } \\
\text { considered, for the dioxin-induced health effects } \\
\text { we applied lifetime probabilities and not annual } \\
\text { probabilities of disease, causing an } \\
\text { overestimation of the risks associated with dioxin } \\
\text { exposure. }\end{array}$ \\
\hline & $\begin{array}{l}\text { Overlapping cases of } \\
\text { disease/co-morbidity }\end{array}$ & $\begin{array}{l}\text { We did not account for the fact that cases of } \\
\text { disease may count double in the DALY estimates, } \\
\text { e.g. cases of CRC and non-cardia stomach cancer } \\
\text { attributed a high processed meat consumption }\end{array}$ \\
\hline
\end{tabular}




\begin{tabular}{|c|c|}
\hline & $\begin{array}{l}\text { which impacts both. However, it unlikely that an } \\
\text { individual will be diagnosed with both cancer } \\
\text { types within the same year. We expect this to } \\
\text { cause an over-estimation of the disease } \\
\text { incidences causing an over-estimation of the final } \\
\text { DALY estimates for each scenario (reference and } \\
\text { alternative scenarios) which may impact the final } \\
\text { DALY difference estimate as well. }\end{array}$ \\
\hline $\begin{array}{l}\text { Overall evaluation } \\
\text { of unquantified } \\
\text { uncertainty }\end{array}$ & $\begin{array}{l}\text { In general, we applied a conservative approach } \\
\text { when making assumptions favoring especially } \\
\text { toxicological risks associated with consumption } \\
\text { of fish. However, uncertainties around e.g. } \\
\text { unidentified compounds or health effects may as } \\
\text { well cause an underestimation of risks. }\end{array}$ \\
\hline
\end{tabular}

Table 6. Unquantified sources of uncertainty of the final DALY difference estimates. Abbreviations: bw: body weight; CRC: colorectal cancer; DALY: disability-adjusted life year; DHA: docosahexaenoic acid; dl-PCB: dioxin-like polychlorinated biphenyl; DW: disability weight; EPA: eicosapentaenoic acid; IQ: intelligence quotient; RBA: risk-benefit assessment; RR: relative risk

\section{Conclusions}

In conclusion, our findings support the recommendations on increasing consumption of fish while decreasing consumption of red and processed meat in the Danish population. We considered the health effects associated with consumption of fish, red and processed meat and with exposure to contaminants and two fatty acids in these foods. We found that up to approximately 7,000 healthy life-years could be gained each year in Denmark if all adult individuals increased the consumption 
of fish to $350 \mathrm{~g} /$ week and at the same time decreased the consumption of red and processed meat. The largest benefit was estimated when at least half of the total amount of fish consumed was fatty. Our study also showed that especially women who plan to become pregnant in the near future should limit the consumption of large predatory fish species such as tuna. However, it is important to stress that our findings show that this subgroup should not limit the consumption of small and fatty fish species to below 200-350 g/week, as the beneficial effects appear to outweigh the adverse effects of $\mathrm{MeHg}$ and dioxins at these amounts.

\section{Acknowledgements}

We thank Tue Christensen for retrieving the consumption data from DANSDA 2011-2013. This work was funded through the Metrix project by the Danish Ministry for Environment and Food. 


\section{References}

Ahlborg UG, Brouwer A, Fingerhut MA, Jacobson JL, Jacobson SW, Kennedy SW, et al. 1992. Impact of polychlorinated dibenzo-p-dioxins, dibenzofurans, and biphenyls on human and environmental health, with special emphasis on application of the toxic equivalency factor concept. Eur. J. Pharmacol. Environ. Toxicol. 228:179-199; doi:10.1016/09266917(92)90029-C.

Becker W, Darnerud PO, Petersson-Grawé K. 2007. Risks and benefits of fish consumption. A riskbenefit analysis based on the occurrence of dioxin/PCB, methyl mercury, n-3 fatty acids and vitamin D in fish. National Food Administration Report Series No. 12.

Berjia FL, Hoekstra J, Andersen R, Poulsen M, Nauta M. 2012. Risk-benefit assessment of coldsmoked salmon: microbial risk versus nutritional benefit. Eur. J. Food Res. Rev. 2: 49-68.

Bingham S, Gill C, Welch A, Cassidy A, Khaw K, Sneyd M, et al. 1994. Comparison of dietary assessment methods in nutritional epidemiology: weighed records v. $24 \mathrm{~h}$ recalls, foodfrequency questionnaires and estimated-diet records. Br. J. Nutr. 72:619-643; doi:10.1079/BJN19940064.

Boas M, Feldt-Rasmussen U, Skakkebæk NE, Main KM. 2006. Environmental chemicals and thyroid function. Eur. J. Endocrinol. 154:599-611; doi:10.1530/eje.1.02128.

Bouvard V, Loomis D, Guyton KZ, Grosse Y, Ghissassi FE 1, Benbrahim-Tallaa L, et al. 2015. Carcinogenicity of consumption of red and processed meat. Lancet. Oncol. 16:1599-1600; doi:10.1016/S1470-2045(15)00444-1.

Cohen JT, Bellinger DC, Connor WE, Kris-Etherton PM, Lawrence RS, Savitz DA, et al. 2005. A 
quantitative risk-benefit analysis of changes in population fish consumption. Am. J. Prev. Med. 29:325-334; doi:10.1016/j.amepre.2005.07.003.

Devleesschauwer B, Haagsma JA, Angulo FJ, Bellinger DC, Cole D, Döpfer D, et al. 2015. Methodological framework for World Health Organization estimates of the global burden of foodborne disease. PLoS One 10:1-20; doi:10.1371/journal.pone.0142498.

Devleesschauwer B, Havelaar AH, Maertens De Noordhout C, Haagsma JA, Praet N, Dorny P, et al. 2014a. Calculating disability-adjusted life years to quantify burden of disease. Int. J. Public Health 59:565-569; doi:10.1007/s00038-014-0552-z.

Devleesschauwer B, Maertens De Noordhout C, Smit SA, Duchateau L, Dorny P, Stein C, et al. 2014b. Quantifying burden of disease to support public health policy in Belgium: opportunities and constraints. BMC Public Health 14:1-8; doi:10.1186/1471-2458-14-1196.

Dietary Guidelines Advisory Committee. 2010. Report of the Dietary Guidelines Advisory Committee on the Dietary Guidelines for Americans, 2010, to the Secretary of Agriculture and the Secretary of Health and Human Services. U.S. Department of Agriculture, Agricultural Research Service. 1-445. Available: http://www.ncbi.nlm.nih.gov/pubmed/8677055 [accessed 18 January 2018].

Domingo JL. 2016. Nutrients and Chemical Pollutants in Fish and Shellfish. Balancing Health Benefits and Risks of Regular Fish Consumption. Crit. Rev. Food Sci. Nutr. 56:979-988; doi:10.1080/10408398.2012.742985.

Domingo JL, Nadal M. 2017. Carcinogenicity of consumption of red meat and processed meat: A review of scientific news since the IARC decision. Food Chem. Toxicol. 105:256-261; doi:10.1016/j.fct.2017.04.028. 
DTU. 2017. Fooddata R2, National Food Institute, Technical University of Denmark. Available: http://frida.fooddata.dk/ [accessed 25 January 2017].

EFSA CONTAM Panel. 2012. EFSA Panel on Contaminants in the Food Chain (CONTAM); Scientific Opinion on the risk for public health related to the presence of mercury and methylmercury in food. EFSA J. 10(12):2985 [241 pp]; doi:10.2903/j.efsa.2012.2985.

EFSA NDA Panel. 2010. EFSA Panel on Dietetic Products, Nutrition, and Allergies (NDA); Scientific Opinion on Dietary Reference Values for fats, including saturated fatty acids, polyunsaturated fatty acids, monounsaturated fatty acids, trans fatty acids, and cholesterol. EFSA J. 2010;8(3):1461 [107 pp.]; doi:10.2903/j.efsa.2010.1461.

EFSA NDA Panel. 2014. Scientific Opinion on health benefits of seafood (fish and shellfish) consumption in relation to health risks associated with exposure to methylmercury. EFSA J. 12(7):3761 [80 pp.]; doi:10.2903/j.efsa.2014.3761.

EFSA Scientific Committee. 2015. Statement on the benefits of fish/seafood consumption compared to the risks of methylmercury in fish/seafood. EFSA J. 13(1):3982 [36 pp.]; doi:10.2903/j.efsa.2015.3982.

FAO/WHO. 2011. Report of the Joint FAO/WHO Expert Consultation on the Risks and Benefits of Fish Consumption. Rome 2010, Food and Agriculture Organization of the United Nations; World Health Organization. Available: http://www.fao.org/docrep/014/ba0136e/ba0136e00.pdf [accessed 18 January 2018].

FAO. 2010. Fats and fatty acids in human nutrition - Report of an expert consultation. Geneva 2008. FAO Food and Nutrition Paper 91, 2010. 1-166; doi:978-92-5-106733-8. Available: http://www.ncbi.nlm.nih.gov/pubmed/21812367 [accessed 18 January 2018]. 
FDA. 2014. A quantitative assessment of the net effects on fetal neurodevelopment from eating commercial fish (as measured by IQ and also by early age verbal development in children). May 2014. U.S. Food and Drug Administration. Available: https://www.fda.gov/downloads/food/foodborneillnesscontaminants/metals/ucm396785.pdf [accessed 18 January 2018].

Gao YX, Zhang HX, Li JG, Zhang L, Yu XW, He JL, et al. 2015. The Benefit Risk Assessment of Consumption of Marine Species Based on Benefit-Risk Analysis for Foods (BRAFO)-tiered Approach. Biomed. Environ. Sci. 28:243-52; doi:10.3967/bes2015.035.

GBD 2016 Risk Factor Collaborators. 2017. Global, regional, and national comparative risk assessment of 84 behavioural, environmental and occupational, and metabolic risks or clusters of risks, 1990-2016: A systematic analysis for the Global Burden of Disease Study 2016. Lancet 390:1345-1422; doi:10.1016/S0140-6736(17)32366-8.

Gibb H, Devleesschauwer B, Bolger PM, Wu F, Ezendam J, Cliff J, et al. 2015. World Health Organization estimates of the global and regional disease burden of four foodborne chemical toxins, 2010: a data synthesis. F1000Research 4:1-12; doi:10.12688/f1000research.7340.1.

Haddow JE, Palomaki GE, Allan WC, Williams JR, Knight GJ, Gagnon J, et al. 1999. Maternal Thyroid Deficiency during Pregnancy and Subsequent Neuropsychological Development of the Child. N. Engl. J. Med. 341: 549-555.

Hay SI, Abajobir AA, Abate KH, Abbafati C, Abbas KM, Abd-Allah F, et al. 2017. Global, regional, and national disability-adjusted life-years (DALYs) for 333 diseases and injuries and healthy life expectancy (HALE) for 195 countries and territories, 1990-2016: a systematic analysis for the Global Burden of Disease Study 2016. Lancet 390:1260-1344; doi:10.1016/S0140-6736(17)32130-X. 
Hellberg RS, Dewitt CAM, Morrissey MT. 2012. Risk-Benefit Analysis of Seafood Consumption: A Review. Compr. Rev. Food Sci. Food Saf. 11:490-517; doi:10.1111/j.15414337.2012.00200.x.

Hibbeln JR, Davis JM, Steer C, Emmett P, Rogers I, Williams C, et al. 2007. Maternal seafood consumption in pregnancy and neurodevelopmental outcomes in childhood (ALSPAC study): an observational cohort study. Lancet 369:578-585; doi:10.1016/S0140-6736(07)60277-3.

Hoekstra J, Hart A, Owen H, Zeilmaker M, Bokkers B, Thorgilsson B, et al. 2013. Fish, contaminants and human health: Quantifying and weighing benefits and risks. Food Chem. Toxicol. 54:18-29; doi:10.1016/j.fct.2012.01.013.

Hsi HC, Hsu YW, Chang TC, Chien LC. 2016. Methylmercury Concentration in Fish and RiskBenefit Assessment of Fish Intake among Pregnant versus Infertile Women in Taiwan. PLoS One 11:1-14; doi:10.1371/journal.pone.0155704.

IARC. 2015. IARC Monographs evaluate consumption of red meat and processed meat. Available: https://www.iarc.fr/en/media-centre/pr/2015/pdfs/pr240_E.pdf [accessed 10 April 2017].

IARC (International Agency for Research on Cancer). 1997. Polychlorinated dibenzo-para-dioxins and polychlorinated dibenzofurans. IARC Monogr Eval Carcinog Risk Hum 69: 1-666.

Jacobs S, Sioen I, Jacxsens L, Domingo JL, Sloth JJ, Marques A, et al. 2017. Risk assessment of methylmercury in five European countries considering the national seafood consumption patterns. Food Chem. Toxicol. 104:26-34; doi:10.1016/j.fct.2016.10.026.

JECFA. 2002. Evaluation of certain food additives and contaminants - fifty-seventh report of the Joint FAO/WHO Expert Committee on Food Additives. Geneva 2002. World Health Organization technical report series. 909: 1-186. 
Knudsen VK, Gille M-B, Nielsen TH, Christensen T, Fagt S, Biltoft-Jensen A. 2011. Relative validity of the pre-coded food diary used in the Danish National Survey of Diet and Physical Activity. Public Health Nutr. 14:2110-6; doi:10.1017/S1368980011001650.

Larsen EH, Andersen NL, Moller A, Petersen A, Mortensen GK, Petersen J. 2002. Monitoring the content and intake of trace elements from food in Denmark. Food Addit. Contam. 19:33-46; doi:10.1080/02652030110087447.

Larsen JC, Nørhede P. 2013. Polychlorinated dibenzo-p-dioxins (PCDDs), dibenzofurans (PCDFs) and biphenyls (PCBs). Evaluation of health hazards and estimation of a quality criterion in soil. Danish Environ. Prot. Agency, Copenhagen 1-50.

Lim SS, Vos T, Flaxman AD, Danaei G, Shibuya K, Adair-Rohani H, et al. 2012. A comparative risk assessment of burden of disease and injury attributable to 67 risk factors and risk factor clusters in 21 regions, 1990-2010: A systematic analysis for the Global Burden of Disease Study 2010. Lancet 380:2224-2260; doi:10.1016/S0140-6736(12)61766-8.

Mozaffarian D, Rimm EB. 2006. Fish Intake, Contaminants, and Human Health: Evaluating the Risks and the Benefits. Jama 296:1885-1900; doi:10.1001/jama.296.15.1885.

Norat T, Chan D, Lau R, Aune D, Vieira R. 2010. WCRF/AICR Systematic Literature Review Continuous Update Project Report - The Associations between Food, Nutrition and Physical Activity and the Risk of Colorectal Cancer. Continuous Update Project. Available: http://www.wcrf.org/sites/default/files/SLR_colorectal_cancer_2010.pdf [accessed 1 August 2017].

Norat T, Vierira AR., Chan D, Aune D, Abar L, Navarro D, et al. 2015. World Cancer Research Fund International Systematic Literature Review - The Associations between Food, Nutrition 
and Physical Activity and the Risk of Stomach Cancer. Continuous Update Project. Available: http://www.wcrf.org/sites/default/files/Stomach-Cancer-SLR-2015.pdf [accessed 1 August 2017].

Nordic Council of Ministers. 2014. Nordic Nutrition Recommendations 2012 - Integrating nutrition and physical activity. 5th ed. Norden:Copenhagen, Denmark.

Oken E, Østerdal ML, Gillman MW, Knudsen VK, Halldorsson TI, Strøm M, et al. 2008a. Associations of maternal fish intake during pregnancy and breastfeeding duration with attainment of developmental milestones in early childhood: a study from the Danish National Birth Cohort. Am. J. Clin. Nutr. 88:789-96; doi:88/3/789 [pii].

Oken E, Radesky JS, Wright RO, Bellinger DC, Chitra J, Kleinman KP, et al. 2008b. Maternal fish intake during pregnancy, blood mercury, and child cognition at age 3 years in a US cohort. Am. J. Epidemiol. 167:1171-1181; doi:10.1093/aje/kwn034.

Oken E, Wright RO, Kleinman KP, Bellinger D, Amarasiriwardena CJ, Hu H, et al. 2005. Maternal fish consumption, hair mercury, and infant cognition in a U.S. cohort. Environ. Health Perspect. 113:1376-1380; doi:10.1289/ehp.8041.

Pedersen AN, Christensen T, Knudsen J, Matthiessen VK, Rosenlund-Sørensen M, Biltoft-Jensen A, et al. 2015. Danskernes kostvaner 2011-2013. Hovedresultater [Dietary habits in Denmark 2011-2013. Main results]. National Food Institute, Technical University of Denmark. Søborg, Denmark. 1-209. Available: http://www.food.dtu.dk//media/Institutter/Foedevareinstituttet/Publikationer/Pub-2015/Rapport_DanskernesKostvaner-2011-2013.ashx?la=da [accessed 1 June 2016].

Persson M, Fagt S, Pires SM, Poulsen M, Vieux F, Nauta MJ. 2018. Use of Mathematical 
Optimization Models to Derive Healthy and Safe Fish Intake. J. Nutr. 148:275-284; doi:10.1093/jn/nxx010.

Petersen A, Fromberg A, Andersen JH, Sloth JJ, Granby K, Duedahl-Olesen L, et al. 2015a. Chemical contaminants - Food Monitoring 2004-2011. 3rd edition. National Food Institute, Technical University of Denmark.

Petersen A, Fromberg A, Andersen JH, Sloth JJ, Granby K, Duedahl-Olesen L, et al. 2015b. Chemical Contaminants - Food Monitoring 2012-2013. 1st edition. National Food Institute, Technical University of Denmark.; doi:10.1016/B978-0-12-064477-3.50018-7.

Pouillot R, Delignette-Muller ML. 2010. Evaluating variability and uncertainty separately in microbial quantitative risk assessment using two R packages. Int. J. Food Microbiol. 142:330_ 340; doi:10.1016/j.ijfoodmicro.2010.07.011.

R Core Team. 2017. R: A language and environment for statistical computing. R Foundation for Statistical Computing, Vienna, Austria. Available: https://www.r-project.org/.

Rideout K, Kosatsky T. 2017. Fish for Dinner? Balancing Risks, Benefits, and Values in Formulating Food Consumption Advice. Risk Anal. 37:2041-2052; doi:10.1111/risa.12769.

Sælensminde K, Johansson L, Helleve A. 2016. Samfunnsgevinster av å følge Helsedirektoratets kostråd. Available:

https://helsedirektoratet.no/Lists/Publikasjoner/Attachments/1216/Samfunnsgevinster av å følge Helsedirektoratets kostråd IS-2451.pdf [accessed 10 December 2017].

Scientific Committee on Food. 2000. Opinion of the SCF on the risk assessment of dioxins and dioxin-like PCBs in Food. Adopted on 22 November 2000. European Commission. 
Scientific Committee on Food. 2001. Opinion of the SCF on the Risk Assessment of Dioxins and Dioxin-like PCBs in Food. Update based on new scientific information available since the adoption of the SFC opinion of 22nd november 2000. Adopted on 30 May 2001. European Commission.

Sioen I, De Henauw S, Verbeke W, Verdonck F, Willems JL, Van Camp J. 2008. Fish consumption is a safe solution to increase the intake of long-chain n-3 fatty acids. Public Health Nutr. 11:1107-1116; doi:10.1017/S1368980007001450.

Sirot V, Leblanc J-C, Margaritis I. 2012. A risk-benefit analysis approach to seafood intake to determine optimal consumption. Br. J. Nutr. 107:1812-22; doi:10.1017/S0007114511005010.

Statistics Denmark. Statistikbanken. Available: http://www.statistikbanken.dk/statbank5a/default.asp?w=1536 [accessed 18 July 2017].

Tetens I, Andersen LB, Astrup A, Mejborn UH, Gondolf Kjeld H, Marianne UJ, et al. 2013a. Evidensgrundlaget for danske råd om kost og fysisk aktivitet [The evidence-base for the Danish guidelines for diet and physical activity]. National Food Institute, Technical University of Denmark. Søborg, Denmark.

Tetens I, Hoppe C, Andersen LF, Helldán A, Lemming EW, Trolle E, et al. 2013b. Nutritional evaluation of lowering consumption of meat and meat products in the Nordic context.

The Danish National eHealth Authority. eSundhed. Available: www.esundhed.dk [accessed 20 July 2017].

The Scientific Advisory Committee on Nutrition. 2010. Iron and Health. TSO:London, UK.

US EPA. 2012. EPA's Reanalysis of Key Issues Related to Dioxin Toxicity and Response to NAS 
Comments, Volume 1 (CAS No. 1746-01-6). U.S. Environmental Protection Agency, Washington, DC. Available:

https://cfpub.epa.gov/ncea/iris/iris_documents/documents/supdocs/dioxinv1sup.pdf [accessed 15 January 2017].

Van den Berg M, Birnbaum LS, Denison M, De Vito M, Farland W, Feeley M, et al. 2006. The 2005 World Health Organization reevaluation of human and mammalian toxic equivalency factors for dioxins and dioxin-like compounds. Toxicol. Sci. 93:223-241; doi:10.1093/toxsci/kfl055.

van der Voet H, de Mul A, van Klaveren J. 2007. A probabilistic model for simultaneous exposure to multiple compounds from food and its use for risk-benefit assessment. Food Chem. Toxicol. 45:1496-1506; doi:10.1016/j.fct.2007.02.009.

Van Horn L, McCoin M, Kris-Etherton PM, Burke F, Carson JAS, Champagne CM, et al. 2008. The Evidence for Dietary Prevention and Treatment of Cardiovascular Disease. J. Am. Diet. Assoc. 108:287-331; doi:10.1016/j.jada.2007.10.050.

Van Leeuwen FXR, Feeley M, Schrenk D, Larsen JC, Farland W, Younes M. 2000. Dioxins: WHO's tolerable daily intake (TDI) revisited. Chemosphere 40:1095-1101; doi:10.1016/S0045-6535(99)00358-6.

VKM. 2014. Benefit-risk assessment of fish and fish products in the Norwegian diet - an update. Scientific Opinion of the Scientific Steering Committee. VKM Report 15 [293 pp]. Oslo, Norway.; doi:10.9734/EJNFS/2015/18605. Available: https://vkm.no/download/18.2994e95b15cc54507161ea1a/1498222018046/0a646edc5e.pdf [accessed 16 March 2016]. 
WCRF/AICR. 2011. Continous Update Project Report. Food, Nutrition, Physical Activity, and the Prevention of Colorectal Cancer. Available: http://www.wcrf.org/sites/default/files/ColorectalCancer-2011-Report.pdf [accessed 10 May 2017].

WCRF/AICR. 2016. Continuous Update Project Report: Diet, nutrition, physical activity and stomach cancer. Available: http://www.wcrf.org/sites/default/files/Stomach-Cancer-2016Report.pdf [accessed 2 July 2017].

WCRF/AICR. 2007. Food, Nutrition, Physical Activity, and the Prevention of Cancer: a Global Perspective. Available: http://www.aicr.org/assets/docs/pdf/reports/Second_Expert_Report.pdf [accessed 2 March 2016].

WHO. 2003. Diet, nutrition and the prevention of chronic diseases: report of a joint WHO/FAO expert consultation. WHO Tech. Rep. Ser. 916. Available: http://eutils.ncbi.nlm.nih.gov/entrez/eutils/elink.fcgi?dbfrom=pubmed\&id=12768890\&retmod $\mathrm{e}=$ ref\&cmd=prlinks\%5Cnpapers3://publication/uuid/734F6B31-260B-4545-A8E457F7D35DDEB8.

WHO. 2000. Executive summary of the Assessment of the health risk of dioxins: Re-evaluation of the tolerable daily intake (TDI). WHO Consultation, May 1998, Geneva.; doi:10.1080/713810655. Available: http://www.who.int/ipcs/publications/en/exe-sum-final.pdf [accessed 15 December 2016].

WHO. 2008. Guidance for Identifying Populations At Risk From Mercury Exposure. Exposure; doi:10.1289/ehp.7856. Available: http://www.who.int/foodsafety/publications/chem/mercuryexposure.pdf?ua=1 [accessed 16 May 2018]. 
WHO. 2017. WHO methods and data sources for global burden of disease estimates 2000-2015.

Global Health Estimates Technical Paper WHO/HIS/HSI/GHE/2017.1. Available:

http://www.who.int/healthinfo/global_burden_disease/GlobalDALYmethods_2000_2015.pdf [accessed 21 May 2017].

Ygil KH. 2013. Mål, vægt og portionsstørrelser på fødevarer [Dimensions, weight and portion sizes of foods]. National Food Institute, Technical University of Denmark. Søborg, Denmark. 1-60. Available: http://www.food.dtu.dk/english//media/Institutter/Foedevareinstituttet/Publikationer/Pub-2013/Rapport_Maal-vaegt-ogportionsstoerrelser-paa-foedevarer.ashx?la=da [accessed 22 January 2018].

Zeilmaker MJ, Hoekstra J, van Eijkeren JCH, de Jong N, Hart A, Kennedy M, et al. 2013. Fish consumption during child bearing age: A quantitative risk-benefit analysis on neurodevelopment. Food Chem. Toxicol. 54:30-34; doi:10.1016/j.fct.2011.10.068. 


\section{Highlights}

- We quantified the health impact of substituting red and processed meat with fish to reach $350 \mathrm{~g}$ of fish/week in a Danish diet.

- We compared the current consumption with four scenarios investigating consumption of different fish species.

- We found an overall beneficial effect of the substitution when consumption of large predatory fish was low.

- A larger benefit was observed when at least half of the fish was fatty.

- Pregnant women should limit consumption of large predatory fish, but should not consume $<200-350 \mathrm{~g}$ of small fatty fish/week. 